\title{
Actitudes hacia la renta de garantía de ingresos: solidaridad, culpabilización individual y preferencia nacional
}

\section{Xabier Aierdi Urraza}

Ikuspegi-Observatorio Vasco de Inmigración. Universidad del País Vasco / Euskal Herriko Unibertsitatea (UPV/EHU)

<xabier.aierdi@ehu.eus>

\section{Gorka Moreno Márquez}

Ikuspegi-Observatorio Vasco de Inmigración. Universidad del País Vasco / Euskal Herriko Unibertsitatea (UPV/EHU)

<gorka.moreno@ehu.eus>

Artikulu honetan hausnartu nahi dugu euskal herritarrek diru-sarrerak bermatzeko errentaren (DBE) iritziaren inguruan, betiere prestazio ekonomiko horren inguruan gertatzen ari den eztabaida aberasteko asmoz. Baxua da dirulaguntza honen inguruko ezaguera; aitzitik, errealitatetik oso urruti dauden adierazpen eta baieztapen batzuek indartsu diraute, adibidez, prestazio horrek iruzur garrantzitsua du, enplegua bilatzeko motibazioa galtzen da edo immigranteek osaturiko kolektiboak jasotzen duela dirurik gehien. Horrek guztiak erakusten du premiazkoa dela DBEren aldeko defentsa global eta integral bat planteatzea instituzioek egin beharreko esfortzutik, eta bestalde, nabarmendu behar da laguntza horrek pobrezia murriztu eta euskal gizartearen kohesioa indartzeko duen ahalmena.

\section{GAKO-HITZAK:}

Iritzi publikoa, gizarte-bazterketa, gizarte-kohesioa, Euskadi, gizarte-zerbitzuak.
En este artículo reflexionamos sobre la opinión de la ciudadanía vasca en torno a la renta de garantía de ingresos (RGI), intentando así enriquecer el debate actual alrededor de esta prestación económica. El conocimiento sobre esta ayuda es bajo; sin embargo, tienen fuerza en la sociedad vasca algunas afirmaciones y aseveraciones que poco tienen que ver con la realidad, tales como la existencia relevante de fraude en la prestación, su efecto en la desincentivación de la búsqueda de empleo o la excesiva cobertura que ofrece al colectivo inmigrante. Todo ello nos lleva a plantear la necesidad de una defensa global e integral de la RGI por parte de las instituciones para hacer frente a estas percepciones y resaltar el potencial de esta ayuda para reducir la pobreza y fortalecer la cohesión de la sociedad vasca.

\section{PALABRAS Clave:}

Opinión pública, exclusión social, cohesión social, País Vasco, servicios sociales. 
De modo que la elección a la que nos enfrentamos en

la siguiente generación no es entre capitalismo y el comunismo, o el final de la historia y el retorno de la historia, sino entre la política de cohesión basada en unos propósitos colectivos y la erosión de la sociedad mediante la política del miedo.

TONY JUDT (Judt y Snyder, 2012)

\section{Introducción}

La renta de garantía de ingresos (RGI) es una medida de protección social que se imbrica dentro de los programas de rentas mínimas que, a partir de finales de los ochenta, se han ido poniendo en marcha en la mayoría de países de la Unión Europea (Castel, 1997) con el propósito de hacer frente a algunos de los nuevos retos que, en materia de cohesión social, surgían para el Estado del bienestar (Ayala, 2000). Esta renta mínima, en vigor en la Comunidad Autónoma de Euskadi desde 1989 bajo diferentes denominaciones (García Romero, 1999), casi treinta años después es una medida de protección altamente mencionada, tanto en el ámbito político o académico como en el social.

El desarrollo de este programa a lo largo del tiempo ha llegado a situarlo en parámetros similares a los de otros países europeos (Laparra, 2004; Moreno y Fullaondo, 2013) y a colocarlo como el modelo más desarrollado a escala estatal. Así, según un reciente informe del SIIS Centro de Documentación y Estudios (2017: 57), el gasto anual por habitante que se realiza en este programa en el País Vasco asciende a 223,06 euros, una cifra muy superior a los 6,41 de Valencia, los 10,61 de Andalucía o los 18,87 de Madrid. Del mismo modo, del gasto total en rentas mínimas en España en 2015 (1.253.705,332 millones de euros), un $39 \%$ se realiza en el País Vasco (488.330.000 millones) [ibídem: 55]. Estos datos reflejan la importancia y magnitud de la RGI a escala estatal, pero también su relevancia dentro del País Vasco, como principal herramienta para hacer frente a la vulnerabilidad, la exclusión social y a la pobreza.

En los últimos años, el debate en torno a la RGI ha trascendido el ámbito académico, técnico o incluso político, y ha pasado a estar en el centro de debates del ámbito social. Este debate se ha dado sobre todo a lo largo del periodo de crisis económica, y se ha sustentado en ciertas ideas y estereotipos vinculados a las prestaciones y los servicios sociales en general, pero que se han focalizado, en este caso, en la RGI. Entre dichas ideas, cabe destacar la percepción de un auge del fraude o la desincentivación de la búsqueda de empleo como consecuencia de percibir una prestación social. Pero sin duda, vinculado a las dos cuestiones anteriores, ha despuntado un discurso en el que el colectivo inmigrante se convertía en grupo que mejor reflejaba todos estos males y que se convertía en la diana de gran parte de las discusiones y críticas planteadas (Moreno, Fouassier y Martín, 2015).

A través de este artículo queremos realizar una serie de reflexiones para profundizar en este debate y hacer hincapié, a la vez, en aquellas cuestiones que estimamos que son relevantes y están vinculadas al futuro y la pervivencia de una prestación como la RGI. Para ello, hemos analizado diferentes fuentes estadísticas que nos ofrecen datos sobre la opinión y la percepción de la sociedad vasca acerca de la RGI, su gestión, sus requisitos o qué criterios deberían plantearse para su reforma -en especial, hemos utilizado el Estudio sobre renta de garantía de ingresos (RGI), realizado en 2017 por Gizaker a petición del Departamento de Empleo y Políticas Sociales del Gobierno Vasco-. Hemos intentado, partiendo de la compilación de estos datos, ofrecer ideas y reflexionar en torno a cuestiones vinculadas con la RGI en concreto, pero también con el Estado del bienestar en su conjunto, o incluso con el modelo de sociedad que queremos tener aquí y ahora, y en el futuro.

\section{Algunas reflexiones en torno a las actitudes hacia la renta de garantía de ingresos}

\subsection{Grado de conocimiento y valoración de la renta de garantía de ingresos}

El grado de conocimiento existente sobre la renta de garantía de ingresos es alto y sensiblemente mayor al de otros programas similares que se dan en otras comunidades autónomas. Podría decirse que incluso sus detractores han contribuido a su notoriedad ${ }^{1}$. Así, el 86,8\% de la población vasca dice haber oído hablar de la RGI, frente a un 12,9\% que declara no haberlo hecho (Gráfico 1).

Este nivel básico de conocimiento es mayor entre los votantes de Podemos, EH Bildu o PNV, entre los de 46 y 60 años, en el territorio histórico de Araba, entre los que trabajan o están en paro y entre los que tienen estudios medios o universitarios. El conocimiento es significativamente menor en Gipuzkoa (79,8\%), en la población de entre 18 y 29 años (74,7\%), entre estudiantes $(69,6 \%)$ y entre los votantes del PP en las elecciones autonómicas de 2016 (62,5\%). Este último dato es llamativo, sabedores de que en las elecciones locales y forales de 2015 el cuestionamiento de la RGI centró parte de su propuesta político-electoral, al menos en Álava (Gráfico 2).

Ahora bien, únicamente un 42,4\% de la población dice saber dónde solicitarla, mientras que casi seis de cada diez personas de la CAPV (57,6\%) declaran no saberlo. Sin embargo, no siempre es ajustado este conocimiento, porque sólo una cuarta parte de la población (24,8\%) acierta a la hora de señalar el organismo que lo gestiona, Lanbide. Un $11 \%$ cita los servicios sociales, y un 3,5\%, las entidades municipales, anteriores lugares de la gestión -no de la competencia, que era foral-.

${ }^{1}$ La RGI se ha encontrado con detractores, pero de forma paradójica ha articulado igualmente sectores defensores. 


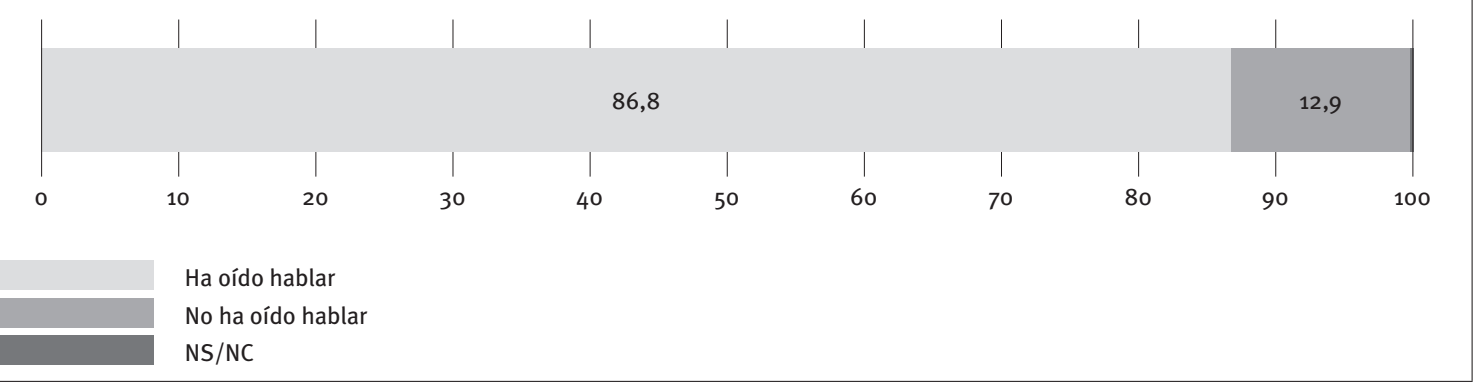

Fuente: Gizaker (2017).

Gráfico 2. Grado de conocimiento de la existencia de la renta de garantía de ingresos, según diferentes variables.

Euskadi, 2017 (\%)

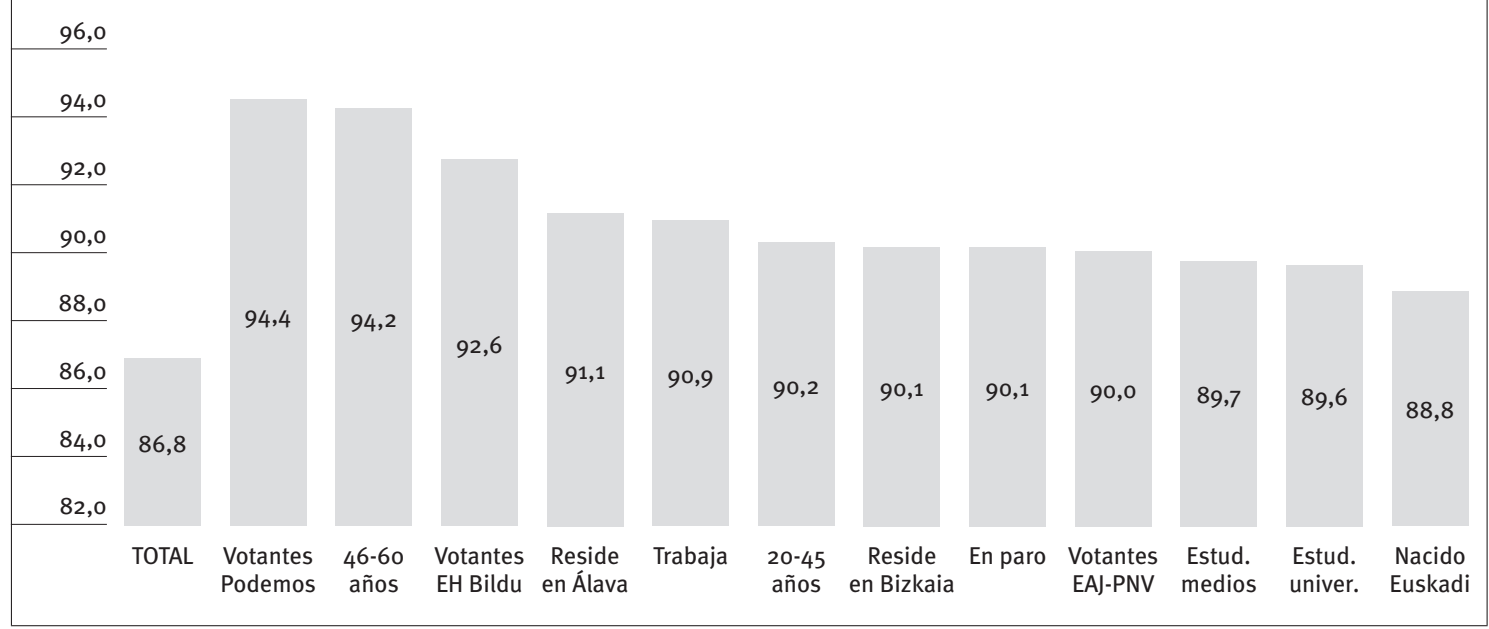

Fuente: Gizaker (2017).

Gráfico 3. Grado de conocimiento en torno al lugar de solicitud de la renta de garantía de ingresos. Euskadi, 2017 (\%)

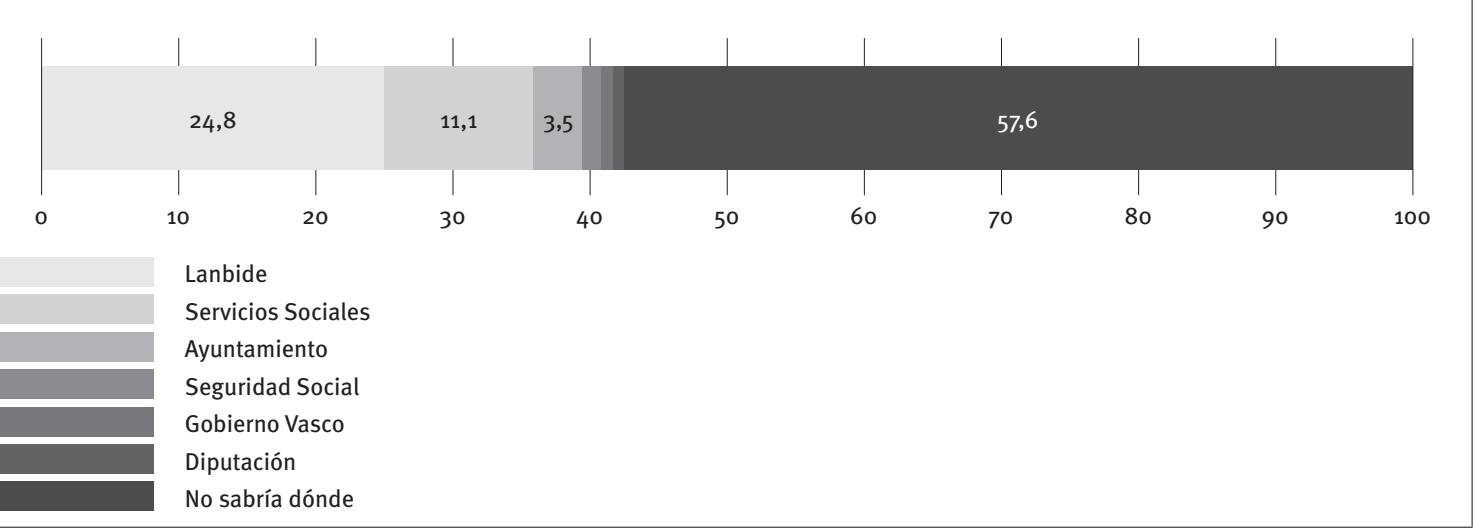

Fuente: Gizaker (2017).

Esta distancia entre haber oído hablar de la RGI y conocer dónde tramitarla nos pone en la pista de un mecanismo que, por recurrente, no deja de ser importante, lo que Alfred Schutz (1974), refiriéndose a las diferentes esferas del conocimiento de la realidad por parte de la sociedad, denominaría 'conocimiento acerca de', un conocimiento imperfecto, confiado, intermediado o lejano. Pero el que sea oído o muy mencionado, no garantiza que sea necesariamente un saber ajustado. Este mecanismo genera, en demasiadas ocasiones, que percepciones de percepciones sirvan de base a los debates sociales y políticos, y al discurrir mismo de la sociedad (Gráfico 3). 
Ahora bien, es altamente significativo que sus potenciales perceptores, especialmente la clase media baja o baja $(49,1 \%)$ o las personas que están en paro $(69,5 \%)$, digan saber dónde solicitarla en caso de necesidad económica. En el extremo opuesto, tenemos a la población estudiante, de la que sólo el 19,1\% declara tener conocimiento sobre este aspecto. En el resto de variables analizadas -sexo, edad, estudios, territorios históricos, clase social, lugar de nacimiento, ideología, situación laboral o recuerdo del voto en las autonómicas de $2016^{2}-$, no se aprecian diferencias significativas.

Sobre el lugar o entidad al que acudir para solicitar esta renta, encontramos nuevamente algunas diferencias significativas muy reseñables, que nos dicen mucho sobre los colectivos que generalmente recurren a la RGI y que están en situación de padecer las formas de exclusión más abiertas: el $35,5 \%$ de la clase media baja o baja, el $28 \%$ de las personas nacidas en el extranjero, el 36,8\% de las personas que tienen entre 30 y 45 años y el $58,9 \%$ de las personas que se encuentran en paro acudirían a Lanbide. Es lo que Schutz llamaría 'conocimiento directo de'. Éste es un conocimiento de uso frente al anterior, que es un conocimiento de referencia indirecta, muy o abiertamente alejado de la realidad.

Una cuarta parte de la población considera que Lanbide realiza una buena gestión de la RGI $(24,9 \%)$, otro $30,6 \%$ la considera regular y un $15,1 \%$ opina que es mala o muy mala. Asimismo, tres de cada diez personas declaran desconocer los parámetros de esta gestión o no responden a la pregunta (Gráfico 4).

Este desconocimiento es mucho mayor cuando se pregunta sobre la idoneidad de que sea Lanbide $u$ otro organismo el que gestione esta renta (Gráfico 5). Es una pregunta difícil de contestar, pues requiere de un conocimiento experto o especializado en cada uno de los tipos de rentas y entidades, de forma que más de cuatro de cada diez personas o no contestan o dicen no saber qué responder. Un $22 \%$ volvería a la situación anterior a 2012, cuando la gestionaban diputaciones forales y municipios, y un $20 \%$ no introduciría cambios y la dejaría como está, en Lanbide. La Seguridad Social o las haciendas forales suponen alrededor del $15 \%$ de las respuestas. Desde luego, a tenor de estos datos no parece conveniente promover cambios en el futuro más corto, no al menos hasta que se consolide la actual situación.

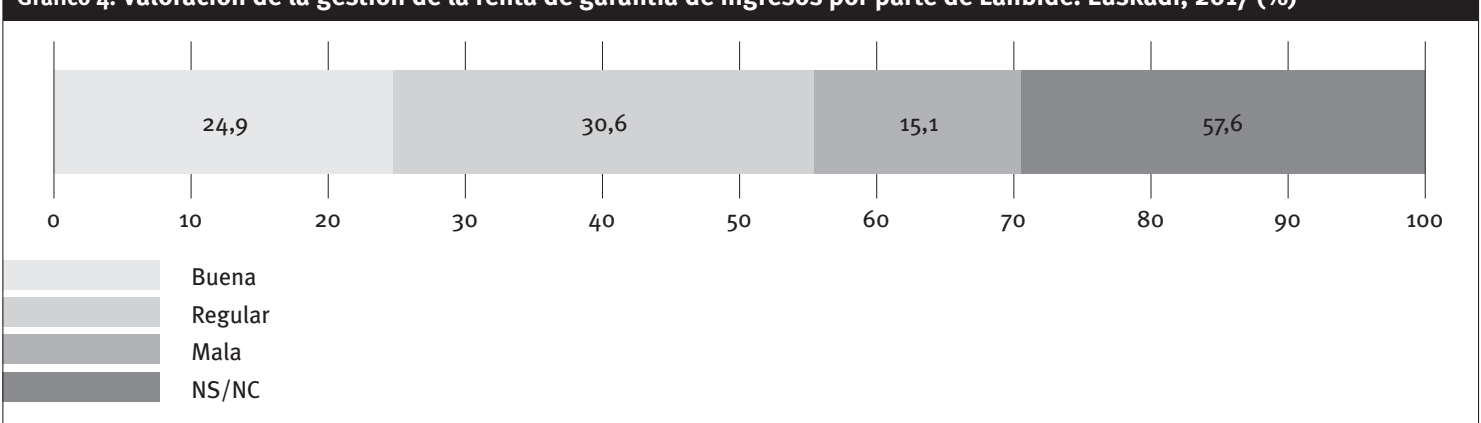

Fuente: Gizaker (2017).

Gráfico 5. Opinión sobre la entidad ideal gestora de la renta de garantía de ingresos. Euskadi, 2017 (\%)

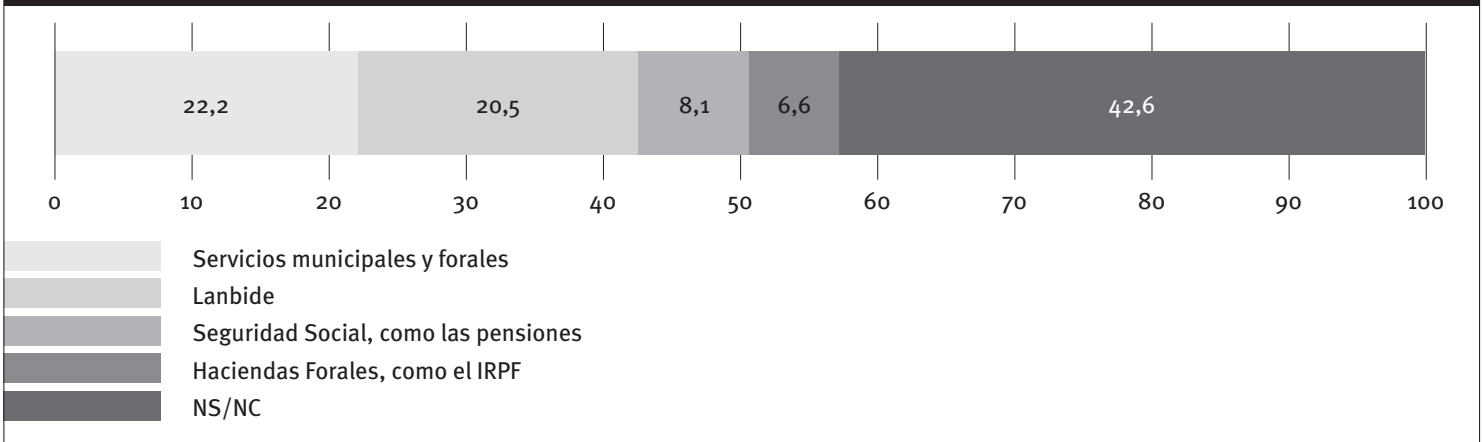

Fuente: Gizaker (2017)

${ }^{2}$ Este conjunto de variables se contemplarán a lo largo de todo el artículo, haciendo referencia sólo a las que presenten puntualmente diferencias significativas por encima o debajo de la media de la población. 


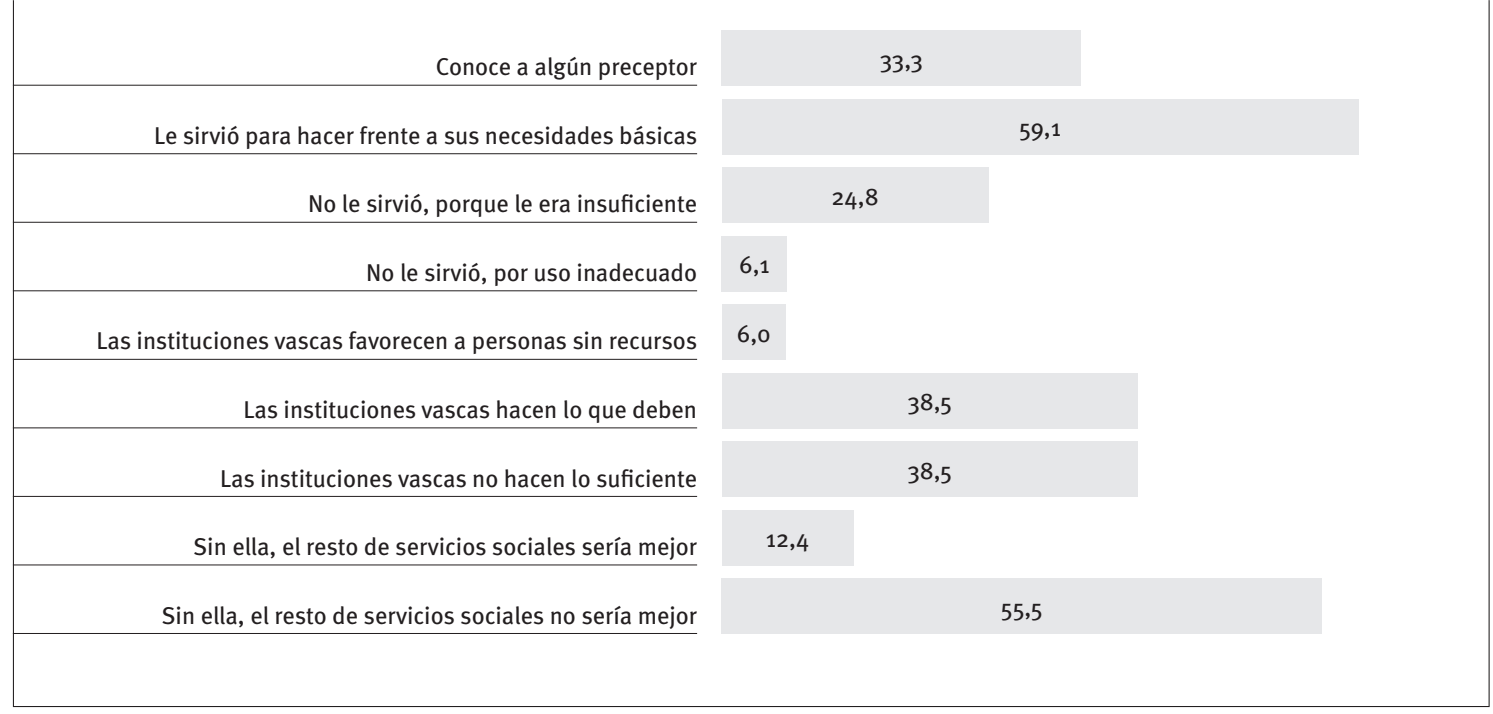

Fuente: Gizaker (2017).

El lema ignaciano de que "en tiempo de tribulación, no hacer mudanza” parece el consejo más conveniente o, en todo caso, como mucho, adoptar ligeros cambios funcionales muy expertamente meditados y previa y prácticamente testados.

No se observan diferencias significativas en las diferentes variables sociodemográficas ni sobre la valoración de la gestión de la RGI por parte de Lanbide, ni sobre la elección de entidades alternativas para su gestión.

Tal como se observa en el Gráfico 6, una tercera parte de la sociedad vasca (33,3\%) dice conocer a alguna persona perceptora, frente a dos tercios que manifiestan lo contrario $(66,1 \%)$. Significativamente, hay más conocedores de perceptores entre los de clase media baja y baja (40,3\%), entre los de 30 y 45 años $(40,9 \%)$ y entre los que se encuentran en paro (46,1\%).

De entre los que conocen a personas perceptoras, seis de cada $(59,1 \%)$ declaran que la prestación les sirvió para hacer frente a las necesidades básicas, mientras que una cuarta parte considera que no, por resultar insuficiente $(24,8 \%)$.

Si seguimos con unos apuntes de valoración general de la RGI y su relación con el quehacer institucional, un $6 \%$ afirma que las instituciones vascas favorecen a las personas sin recursos, casi un $40 \%$ afirma que hacen lo que deben y otro $40 \%$, que no hacen lo suficiente. A grandes rasgos, parece haber un alto acuerdo con las políticas públicas vascas de rentas mínimas, lo que se confirma con el porcentaje de los que piensan que sin la RGI el resto de servicios sociales no sería mejor (55,5\%), frente a un $12,4 \%$ que cree que mejorarían. Es decir, parece que la prestacion no actúa en detrimento del resto de políticas sociales potenciales. A simple vista, por tanto, parece que a pesar de los lunares que podrían detectarse y de las opiniones negativas que pudieran mantenerse, y sobre las que más tarde volveremos, hay un acuerdo relativamente tácito en torno a la conveniencia de la RGI y al papel que las instituciones deben mantener en rentas mínimas, porque mientras que casi la mitad de la población vasca considera que las instituciones hacen lo que deben, lo que es de su responsabilidad y obligación, cuatro de cada diez personas opinan que no hacen lo suficiente. Se acepta lo que hacen, pero se subrayan también sus deficiencias. Además, más de la mitad de la población considera que la RGI no colisiona con el resto de los servicios sociales, no los empeora, frente a un $12,4 \%$ que estima que los perjudica.

Entrando en el amplio ámbito del alcance, requisitos y condiciones que las personas deberían cumplir para poder acceder a la RGI, nos encontramos en un territorio de discursos y actitudes contradictorios, que pocas veces se complementan y más frecuentemente se anulan unos a otros. Otro tanto ocurrirá con las imágenes sociales y laborales con las que se emparenta la RGl3. Así, en un campo de indeterminación muy grande, ante la tesitura de si deben percibirla más personas, un $41,5 \%$ de la población no sabe qué responder o no contesta, un $29,2 \%$ estima que la RGI deberían poder recibirla más personas, un 18,8\% prefiere que siga como está y no se abra a un mayor número de personas, y un $10,5 \%$ cree que la deberían percibir menos personas (Gráfico 7).

3 Según Sowell (1990: 34), los "discursos sociales son importantes porque interpretan, categorizan y clasifican la realidad, pero sobre todo son modos de causación: 'son la base a partir de la cual se buscan los por qué de las cosas"”. 


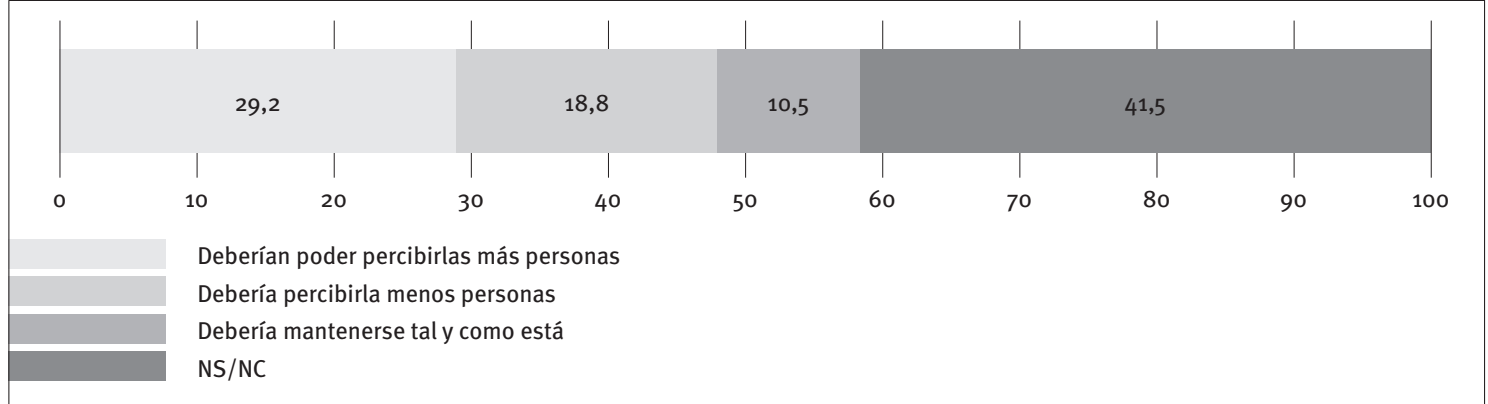

Fuente: Gizaker (2017).

Tras esta no respuesta tan amplia, podemos encontrar dos tipos de silencios. Está el silencio ignorante, por decirlo de alguna forma, en el que por la dificultad del asunto tratado las personas encuestadas no saben emitir una respuesta que recoja su parecer; pero también puede haber un silencio interesado o contrario a la respuesta, basado en la deseabilidad. Conocedoras de que una opinión negativa por una protección es socialmente más difícil de expresar, habrá personas que escojan el silencio como respuesta encubridora de su opinión.

Efectivamente, en el ámbito de las protecciones siempre late lo que sociológicamente se denomina preferencia de los nacionales, o la idea que de que las ayudas se deben restringir a los ciudadanos nacionales (a 'los de casa') y no extenderlas a las personas de nacionalidad extranjera o simplemente foráneas. Tras esta idea tan extendida, pero no necesariamente expresada, late lo que eminentes sociólogos y sociólogas han denominado nacionalismo metodológico ${ }^{4}$, del cual se deriva, entre otras, la idea fuerza que vertebra toda la modernidad de que las fronteras físicas estatales son fronteras morales, y de que la solidaridad debe terminar o termina prácticamente allí donde finalizan las fronteras. Dicho de otro modo: fronteras adentro, lo que sea preciso; fronteras afuera, no nos compete. Pero volveremos sobre esto.

Antes, recurriremos a dos preguntas del cuestionario referidas a la inmigración y a su relación con la RGI. Cuando se inquiere si la inmigración es un problema

${ }_{4}$ El nacionalismo metodológico consiste en pensar que la referencia analítica (y política y legítima) central es el Estado-nación, referencia basada en la idea de que a un Estado corresponde una única nación, una única cultura y una única... (se comience por cualquier otro término, siempre se termina igual). Los grandes sociólogos recientes, como Beck, Giddens o Bauman, han abundado en el análisis y crítica de esta idea. Beck (2002: 9) afirma que:

El Estado-nación se ha convertido en el telón de fondo para la percepción de la sociología. Por eso se podría hablar de un nacionalismo metodológico. La hipótesis clave del nacionalismo es que la humanidad se halla dividida en un número finito de naciones, cada una de las cuales debe cultivar y vivir su propia cultura unitaria, garantizada por el Estado, el Estado-nación. Trasladado a la sociología, esto significa que la mirada sociológica está encerrada en el Estado-nación, que es una forma de ver las sociedades desde el punto de vista del Estado-nación. en Euskadi, el $28 \%$ de los encuestados se posiciona afirmativamente, un $61,1 \%$ niega que constituya un problema y un $11 \%$ no sabe o no contesta. Se observan algunas diferencias estadísticamente significativas, de forma que los de nacionalidad española, las personas con poco nivel de estudios, los nacidos en el resto de comunidades autónomas, los que se autodefinen ideológicamente como de derechas, las personas mayores mayores de 60 años y los votantes del PP intenfisican el carácter problemático de la inmigración, mientras que lo aligeran notablemente las propias personas de nacionalidad extranjera o las nacidas en el extranjero. Con mucha probabilidad, algunos de estos sectores se ven potencialmente perjudicados por la llegada de población inmigrante, y de ahí su peor valoración ${ }^{5}$.

Asimismo, cuando se consulta sobre si habría más menos inmigrantes en caso de que no existiese la RGI, más de la mitad de la población vasca (54,3\%) opina que habría menos. Un $32,7 \%$ estima que la RGI no afecta, y finalmente un $13 \%$ no sabe o no contesta. Esta respuesta viene a decirnos que, para una gran mayoría de la sociedad vasca, la RGI genera el tan popularizado 'efecto llamada', atrayendo inmigración específica con base en esta renta mínima. Este parecer es significativamente mayor entre los de nacionalidad española (55,4\%) que entre los de extranjera (27,3\%), entre los nacidos en el resto de comunidades autónomas $(61,2 \%)$ que en el extranjero (32\%), y entre los que votaron al PNV en las autonómicas de $2016(67,4 \%)^{6}$.

${ }^{5}$ Estos datos coinciden con los perfiles de umbrales de tolerancia que publica anualmente Ikuspegi-Observatorio Vasco de Inmigración: a mayor incertidumbre general o mayor notoriedad pública de la población inmigrante, menor grado de tolerancia, y viceversa (véase Ikuspegi, 2017: 34).

${ }^{6}$ También sobre este aspecto, Ikuspegi ha escrito notables páginas en las que demuestra que el efecto 'selección' del receptor es causa más solvente que el de 'llamada' en la dinamización de los flujos. Los datos de la nueva puesta en marcha de flujos hacia Euskadi desde $\mathbf{2 0 1 5}$ hasta hoy, en los que vuelven a reaparecer orígenes que se consideraban ya exhaustos - como el de la población originaria de Colombia - confirman lo contrario. Por otra parte, dado el mayor porcentaje de inmigración en casi todas las comunidades autónomas de España, difícilmente explican el diferencial atractor que generaría la RGI. Pero cuando de lecturas de la realidad se trata, siempre hemos estado en la posverdad. 


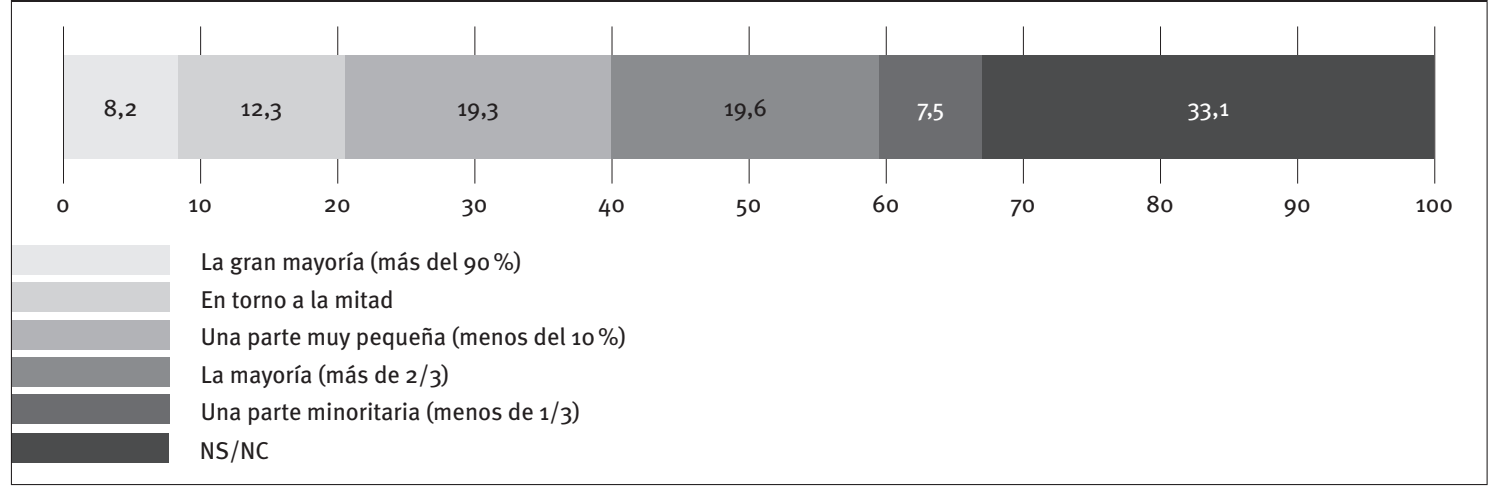

Fuente: Gizaker (2017).

Gráfico 9. Política a seguir con respecto a las personas beneficiarias extranjeras beneficiarias de la renta de garantía de ingresos. Euskadi, 2017 (\%)

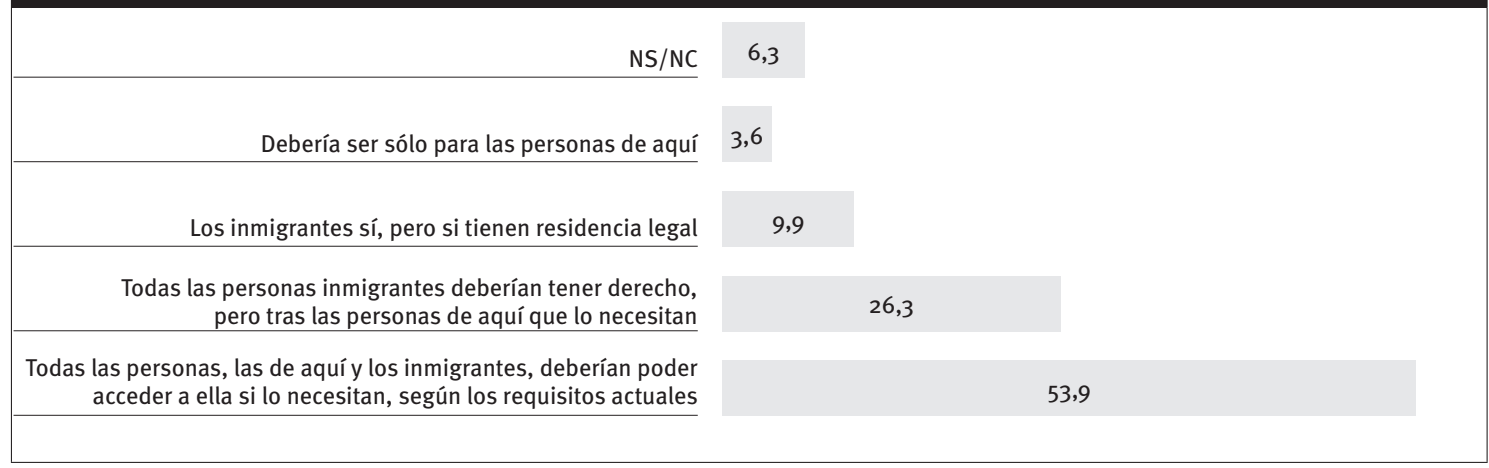

Fuente: Gizaker (2017).

Aunque los procesos inductores de las inmigraciones, o de las emigraciones, suelen ser resultado de complejos procesos de cocausación, es innegable que entre las visiones dominantes de la sociedad vasca también está presente la que mantiene que la inmigración llegaría al País Vasco atraída por la existencia de la RGI. Esta opinión concuerda con la percepción de que son más las personas extranjeras las que estarían percibiendo la RGI.

En la respuesta a la pregunta, se percibe la ligera convicción de que son más los extranjeros que los españoles entre los perceptores de la RGI (Gráfico 8). Habría mayoría española para un $20,5 \%$ de las personas encuestadas, mayoría extranjera para un $27,1 \%$, y un $19,3 \%$ afirma que en torno a la mitad son de nacionalidad española; luego está la incógnita que esconde el alto porcentaje de no respuestas 0 de quienes dicen no saber, muy probablemente una vez instalados en la respuesta silenciada. Aunque los datos objetivos de los perceptores desmienten estas visiones, las debemos tener en cuenta, porque como muy bien se sabe en sociología, la definición de la situación forma parte decisiva de la realidad social, incluso cuando es falsa. Hay además un 33,1\% que o no sabe o no responde, lo que nos lleva a mantener la distinción de silencios que hemos realizado líneas arriba. Por otro lado, constatamos que no se presentan diferencias significativas según otras variables.

Sobre el tiempo de trabajo o empadronamiento que debe transcurrir para poder acceder a la RGI, hay igualmente opiniones divididas. Cuatro de cada diez personas $(41,4 \%)$ son partidarias de no remover la situación y mantenerla como está; una de cada diez (12,2\%), de aligerar los tiempos; y casi tres de cada diez (26,3\%), están a favor de exigir más permanencia de empadronamiento o de trabajo. Finalmente, dos de cada diez $(20,1 \%)$ no se definen. No se observan diferencias significativas según otras variables sociodemográficas, laborales ni políticas.

Por otra parte, cuando se consulta sobre cuál debería ser la política a seguir en la RGI con las personas extranjeras perceptoras, la mitad de la población vasca es partidaria (53,9\%) de que toda la población residente del País Vasco, autóctonos e inmigrantes, accedan a la RGI en igualdad de requisitos (Gráfico 9). Un $26,3 \%$ es partidario de que las personas inmigrantes puedan acceder, pero siempre por detrás de las personas autóctonas; un 9,9\%, únicamente si residen de forma legal; y un 3,6\% declara que la RGI no debería ser accesible a las personas inmigrantes. Un 6,3\% dice no saber o no contesta. No encontramos diferencias significativas, salvo en 
el caso de las personas nacidas en el extranjero, que son lógicamente mucho más partidarias de que el acceso sea universal $(73,5 \%)$.

\section{2. ¿Quién debe poder percibir las ayudas sociales?}

Muy probablemente, pocas de las personas encuestadas conocen los requisitos para el acceso a la RGI, pero la magia social consiste en emitir opiniones y mantener discursos a pesar de que no se conozcan las cuestiones a fondo. Estamos ante opciones preideológicas, reacciones emotivas o actitudes, que son tan o más importantes para el funcionamiento social que la verdad científica o el saber experto. Desconocer este extremo, o incluso considerarlo extravagante, no nos impide tenerlo en cuenta a la hora de focalizar mensajes o de tejer estrategias parcializadas y específicas de sensibilización. En ningún tratado está recogido, salvo en el inédito sobre la deseabilidad del funcionamiento del mundo, que para las personas se anteponga el conocimiento constrastado sobre el percibido.

Toda esta percepción se sintetiza en la pregunta sobre qué harían básicamente si la RGI estuviese en sus manos: un tercio largo de la sociedad vasca (35,3\%) es partidario de endurecer el acceso; un $16,2 \%$, de flexibilizarlo y facilitarlo; y un $22,3 \%$ considera que lo dejaría como está (Gráfico 10). Una vez más, un $26,2 \%$, casi más de un cuarto de la población encuestada no se decanta.

Ante esta pregunta, sí se observan ciertas diferencias significativas (Gráfico 11). La primera, según la nacionalidad. Mientras que los de nacionalidad española son más partidarios de endurecer $(36,2 \%)$, entre los de nacionalidad española y otra extranjera o simplemente extranjera sólo un $14 \%$ es partidario de esta medida. Por edad, mientras que los de 30 a 45 años son más partidarios de endurecer el acceso (43,8\%), los que tienen entre 18 y 29 años son partidarios de flexibilizarlo (33,1\%). Según la actividad, los que trabajan endurecerían el acceso (39,1\%), mientras que los que estudian lo flexibilizarían en mucho mayor grado (42,6\%). Finalmente, según el voto en las elecciones autonómicas de 2016, los que votaron al PNV son más partidarios del endurecimiento (45,2\%), frente a los que votaron a Bildu, que son más partidarios de flexibilizar el acceso (30,7\%). garantia de ingresos?". Euskadi, 2017 (\%)

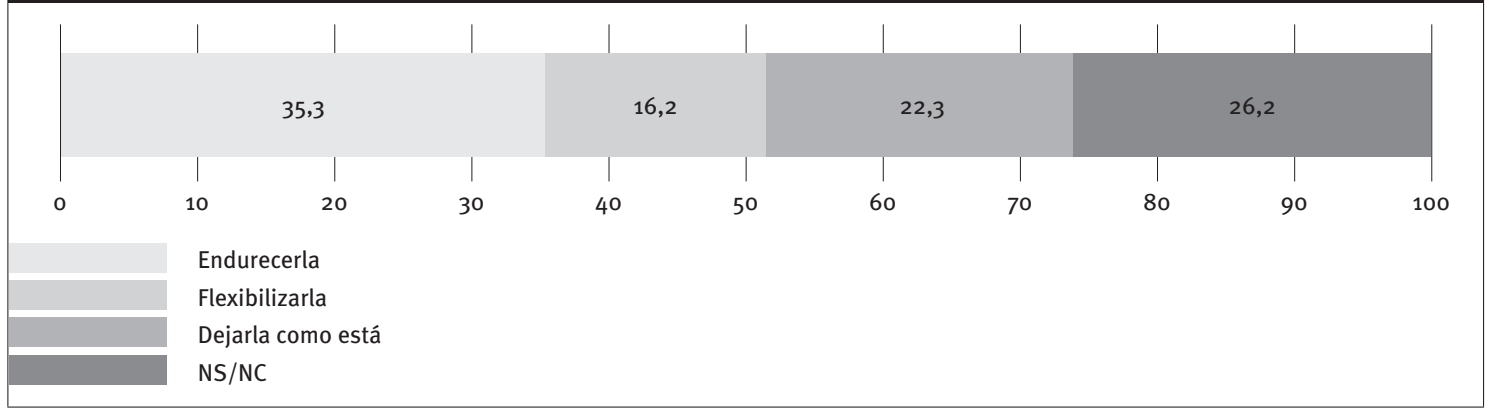

Fuente: Gizaker (2017).

Gráfico 11. Valoraciones sobre la renta de garantía de ingresos. Euskadi, 2017 (\%)

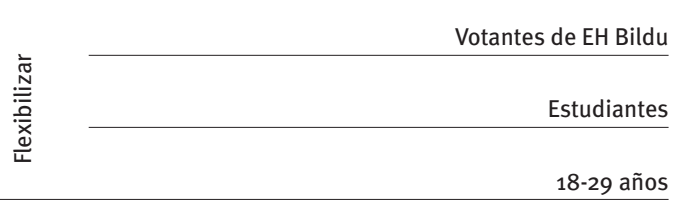

Votantes de EAJ-PNV

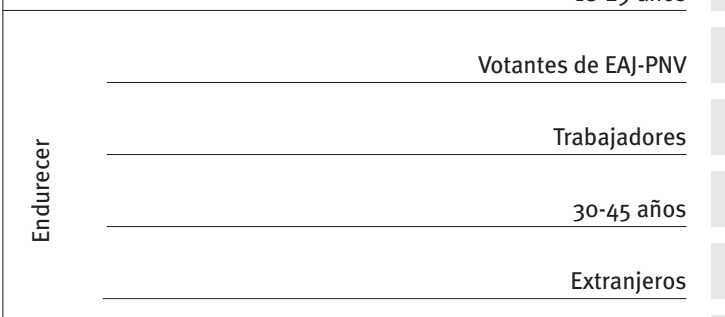

Nacionales españoles
Fuente: Gizaker (2017).
30,7

42,6

33,1

\section{5,2}

39,1

43,8 


\section{3. ¿Es el empleo el mejor integrador social? ¿También hoy?}

A continuación, analizaremos los imaginarios discursivos que normalmente acompañan a las rentas mínimas o, más en general, a todas las rentas de protección social. Partimos de una constatación percibida, pero luego nos adentramos en sus agujeros negros. Para la sociedad vasca, es una constatación (56\%) que las tasas de pobreza de Euskadi son más bajas que las de otras comunidades autónomas gracias a la RGI (Gráfico 12). No lo piensa así el $15 \%$ y un $28,8 \%$ no se decanta. En esta cuestión, no se observan diferencias significativas, por lo que estimamos que la funcionalidad económica de la RGI a la hora de reducir la pobreza no es un tema de debate?. Tras lo visto, no se discute en suma sobre la eficacia de la RGI, sino sobre a quiénes corresponde ser sus beneficiarios legítimos.

Asimismo, hay una práctica unanimidad con respecto a la opinión de que las personas que reciben ayudas sociales las necesitan para vivir. Así lo declara el $80,8 \%$ de la población vasca, frente a un $13 \%$ que opina lo contrario. Únicamente las personas de entre 18 y 29 años $(88,3 \%)$ y los estudiantes $(97,1 \%)$ se distancian significativamente, intensificando esta opinión. En el resto de variables, no se observan diferencias.
Sobre este contexto de funcionalidad y de necesidad social real de la RGI, las opiniones siguientes sí entran en matizaciones que tienen que ver tanto con la forma en que se perciben las prestaciones sociales - normalmente de forma negativa- como con el trasfondo laboral que subyace a ellas: todavía hoy es muy difícil abandonar la lógica del imaginario de la ciudadanía laboral y la idea de que la integración social únicamente debe derivar de la contribución laboral. Los esquemas alternativos 0 complementarios presentan grandes dificultades para abrirse paso. Como afirma Luis Enrique Alonso, da la impresión de que es cuasi imposible salir de la tríada nacionalidad, empleo formal y masculinidad familística (Alonso, 2007), cuando los datos y las tendencias nos indica que es un modelo debilitado, cuando no crecientemente desfasado y en trance de progresiva desaparición, o simplemente útil para una minoría cada vez menor de nuestra sociedad. Este mismo autor sugiere en otra publicación (Alonso, 2001) que es difícil sustentar una sociedad fuerte sobre un empleo débil, que es el que gana terreno de una forma ineludible.

Desde esa perspectiva dominante, es comprensible que la sociedad vasca, como todas las de su entorno, sostenga como condición de seguridad imprescindible lo que no deja de ser una realidad crecientemente circunstancial y coyuntural, porque

Gráfico 12. Diferentes percepciones acerca de la renta de garantía de ingresos. Euskadi, 2017 (\%)

Gracias a ella, las tasas de pobreza de Euskadi son más bajas que las de otras comunidades autónomas

Las personas que reciben ayudas sociales las necesitan para vivir

Si las empresas ofrecieran más y mejor empleo, no habría tantas personas que necesitarían acceder a ella

Para evitar la pobreza, las instituciones públicas no deben ofrecer prestaciones económicas, sino garantizar el acceso...

Acuerdo

Desacuerdo

NS/NC

Fuente: Gizaker (2017).

7 Esta opinión suele ser recurrente también en otras encuestas y se suele confirmar a través de las estadísticas oficiales que cuatrianualmente -bianualmente, a veces- realiza el Órgano Estadístico del Departamento de Empleo y Políticas Sociales del Gobierno Vasco, a través de las Encuestas de Pobreza y Desigualdades Sociales (EPDS). 
opina con rotundidad (84,2\%) que si las empresas ofreciesen más y mejor empleo, tantas y tantas personas no deberían tener que recurrir a las ayudas sociales. Sólo un 8,4\% opina lo contrario. Esta opinión tan extendida no sería preocupante si no tuviéramos en cuenta la creciente polarización y el potente proceso de desigualdad que caracteriza hoy al menguante mercado laboral. La precarización impide la condición de seguridad, pero es desde ahí desde donde se mira la protección social. No termina de abrirse camino la idea de que la protección social es esencialmente inversión social. La protección se sigue equiparando únicamente a gasto inútil, no sólo en la mentalidad dominante de la sociedad, sino también en la de la clase política.

Hace más de veinte años, el fallecido Ulrick Beck (2000: 9) auguraba el esquema de la 'brasileñización de occidente' para describir que, ante o frente el proceso de la universalización de las condiciones laborales europeas en el resto del mundo, iba a operarse la informalización de sus procesos también en Europa. Bauman lo dijo más expresamente (Caballero y Vilaseca, 2003: 11): se ha pasado de los 'ejércitos de reserva' a los 'excedentes' laborales. Un cambio terminológico que resume la mutación laboral de toda una época. Al ejército de reserva se le espera; al excedente, no.
En cambio, es tan potente y tan compartida esta evidencia social de la necesaria supeditación de la integración social a la laboral que no se observan diferencias significativas reseñables. Esta opinión, que, por deseada y compartida, expresa socialmente un anhelo, es, por otra parte, un velo para avistar la modalidad de realidad laboral en la que estamos adentrándonos de forma acelerada. Es un deseo que anula el análisis.

La centralidad del empleo lleva a la opinión también casi unánime $(78,7 \%)$ de que, para evitar la pobreza, las instituciones públicas no deben ofrecer prestaciones económicas, sino garantizar el acceso a un empleo ${ }^{8}$. Únicamente el 13,1\% declara lo contrario. Reseñamos dos diferencias significativas de sentido contrario, pero que indican perfectamente los límites en los que hoy se desarrolla el debate. El $85,5 \%$ de los que votaron a Podemos en las elecciones autonómicas de 2016 intensifican esta opinión de que las instituciones deben garantizar el acceso a un empleo, y responsabilizan a éstas de que efectivamente suceda; el $65,2 \%$ de los votantes del PP opinan en el mismo sentido, pero muy probablemente responsabilizando a las personas del éxito o el fracaso en la búsqueda del empleo, y liberando a las instituciones de este esfuerzo.

Gráfico 13. Percepciones sobre las personas perceptoras de renta de garantía de ingresos. Euskadi, 2017 (\%)

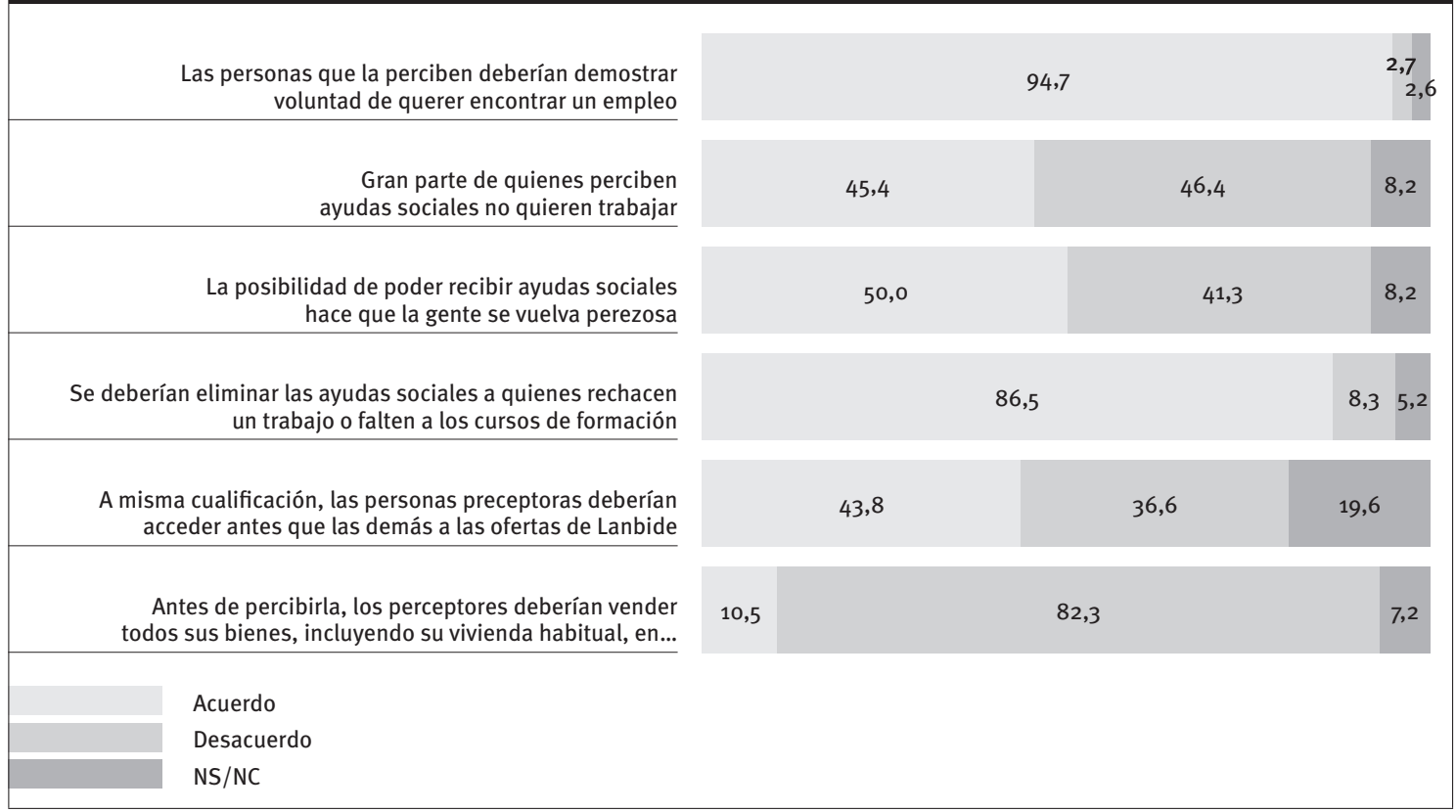

Fuente: Gizaker (2017).

${ }^{8}$ Está muy extendida la idea de que no hay mejor integración social que un buen empleo. A esta idea únicamente le faltan dos precondiciones: 'bueno' y 'empleo'. Como ha acertado a decir un buen analista: "el problema ya no es la tasa de paro, sino la calidad del empleo". Una sociedad con buen empleo puede ser viable con una alta tasa de paro, pero un empleo generalizado de pésima calidad no viabiliza una sociedad sin paro técnico. Véase el caso de los Estados Unidos, con una tasa de paro del $5 \%$ y casi 50 millones de personas pobres, de los cuales 22 millones viven en estado de pobreza severa (Short, 2015). 
Desde la preeminencia de la visión laboral y partiendo de una visión antropológica negativa y culpabilizadora ${ }^{9}$, la carga de la prueba siempre recae en el individuo (Gráfico 13). Aunque previamente hemos visto que ocho de cada diez personas consultadas creen que la RGI se percibe porque se precisa, es el individuo, no la situación, quien debería demostrarlo, con una voluntad indiscutible de encontrar un empleo para poder percibirla. Así lo piensa el $94,7 \%$ de la población vasca, y no se observan diferencias significativas respecto a este punto.

Es un clásico relacionar las ayudas sociales con la nula voluntad de trabajar o con el perverso efecto de la pereza, que suelen ser argumentos recurrentes para mostrar desacuerdo con las rentas, sean mínimas o básicas ${ }^{10}$. Ahora bien, en estos casos las respuestas son menos unánimes. Es similar el porcentaje de personas que opinan que quienes perciben las ayudas sociales no desean trabajar que quienes piensan lo contrario. Es incluso ligeramente superior el desacuerdo que el acuerdo con la afirmación. La única diferencia significativa que observamos ante esta afirmación es la de las personas que o no tienen estudios o tienen únicamente estudios primarios, que normalmente también son quienes conforman lo que se denomina clase blanca pobre o personas autóctonas en zona de vulnerabilidad.

En cambio, sí se presenta mayor acuerdo con la idea de que las ayudas tornan perezosas a las personas (50\%), frente a quienes muestran desacuerdo con la frase ( $41,3 \%)$. De nuevo, intensifican significativamente el acuerdo con esta afirmación las personas sin estudios (58\%), las de clase social media (53,9\%), los que profesan ideología centrista $(58,9 \%) \mathrm{y}$, sobre todo, los votantes del PP (70,8\%).

Asimismo, late siempre una dinámica de recelo y otra de castigo en las rentas mínimas ${ }^{11}$. Estamos ante un

9 La corriente dominante de la mejor sociología del momento sostiene que hoy las contradicciones sistémicas se pagan en términos biográficos: se culpabiliza al individuo de lo que su estructura social e institucional no le suministra: certidumbre y seguridad.

${ }^{10}$ Es un debate ya clásico el que mantuvieron Rawls y Van Parijs sobre si una sociedad debería mantener a los surfistas de Malibú (cit. en ATTAC Madrid, 2013).

${ }^{11}$ Esta mentalidad se extiende mucho más allá del pensamiento conservador, tradicional o de derechas, y la idea o ideología laboralista/incorporadora está muy presente también en la izquierda. Añadimos declaraciones recogidas en la revista Le Monde Diplomatique de septiembre de 2017, realizadas por miembros del Partido Socialdemócrata alemán (SPD):

El que puede trabajar, pero no quiere, no tiene derecho a la solidaridad. El derecho a la pereza no existe en nuestra sociedad (canciller Gerhard Schröder, Bild, 6 de abril de 2001).

Los costes salariales han alcanzado un nivel que ya no es soportable para los asalariados y que impide a los empleadores generar actividad. [...]. Vamos a tener que recortar el gasto del Estado, promover la responsabilidad individual y exigir más esfuerzo por parte de todos (Gerhard Schröder, discurso en el Bundestag, 14 de marzo de 2003).

La miseria no es la pobreza del monedero, sino la pobreza del espíritu. A las clases inferiores, no les falta dinero, les falta cultura. [...] La pobreza resulta de su comportamiento, es una consecuencia de la baja cultura (Walter Wüllenweber, editoria- workfare punitivo, siguiendo así la reinterpretación anglosajona del welfare que se ha dado en las últimas dos décadas (Brodkin y Marston, 2013) y en la que toma fuerza una lógica de derechos y obligaciones (Andersen y Svarer, 2014) en virtud de la cual la persona perceptora de ayudas sociales está obligada a reincorporarse inmediatamente al mercado laboral si quiere poder seguir percibiendo dichas ayudas. Una reforma que ha sido ampliamente criticada tanto por sus contenidos normativos (Shaver, 2002; Waddan, 2003) como por los propios resultados (Macleavy, 2015). Casi nueve de cada diez personas $(86,5 \%)$ son partidarias de eliminar las prestaciones a las personas que rechacen un trabajo o no asistan a los cursos de formación. Esta opinión está extendida socialmente, y concuerda con el imaginario bíblico y moderno-industrial de que hay que ganarse la vida para merecérsela. Únicamente las personas de ideología izquierdista aligeran esta dimensión punitiva, y la rebajan al 78,6\%. Ahora bien, a igual cualificación y como lógica de premio o estímulo, son más los partidarios (43,8\%) que los detractores (36,6\%) a la hora de dar preferencia, ante ofertas de trabajo, a quienes están ligados a Lanbide y a sus cursos. El acuerdo es mayor entre las personas extranjeras (58\%) y entre quienes están en paro ( $51,4 \%)$, y menor entre los que trabajan $(39,3 \%)$. Asimismo, el desacuerdo es mayor entre los nacidos en la CAPV.

Ahora bien, extremar esta opinión tampoco es aceptable para el grueso de la población vasca, y cuando se propone expropiar absolutamente ${ }^{12}$ a las personas para que puedan acceder a la RGI, el 82,3\% muestra su desacuerdo y sólo un 10,5\% está de acuerdo con esta posición. Es tan radical la respuesta negativa a esta frase que no aparecen diferencias significativas reseñables.

Finalmente, otro recurso argumentativo habitual suele ser el de la inviabilidad económica de la RGI, argumento según el cual no es la voluntad o deseo de la persona o de la sociedad la que restringe las protecciones sociales, sino la situación económica, que no podría destinar ese coste a sostenerlas (Gráfico 14). En este caso, se recurre a un argumento supuestamente neutral, que se usa como justificación suprema de qué hacer con las ayudas. Ahora bien, tras esta neutralidad late toda una cosmovisión de conjunto tanto del empleo, considerándolo como único incorporador o integrador social legítimo, como de qué supone inversión social. Esta visión está muy enraizada en todos los sectores sociales, y desgraciadamente

lista, Stern, 16 de diciembre de 2004).

La pobreza no es una cuestión de dinero. [...] Lo importante para una familia es saber gastar el dinero. [...] Una comida en un restaurante rápido no es sólo peor para la salud, sino también más cara que un guiso con verduras de temporada (Renate Schmidt, ministra federal de Familia, Bild am Sonntag, 27 de febrero de 2005).

${ }^{12}$ La afirmación ante la que se pide mostrar el acuerdo o desacuerdo es la siguiente: "antes de percibir la RGI, los perceptores deberían vender todos sus bienes, incluyendo su vivienda habitual, en caso de tenerla". 
El gasto del Gobierno Vasco en renta de garantía de ingresos es demasiado elevado y es necesario reducirlo

Acuerdo

Desacuerdo

NS/NC

Fuente: Gizaker (2017).

Gráfico 15. Opinión acerca de las cuantías para cada tamaño familiar. Euskadi, 2017 (\%)

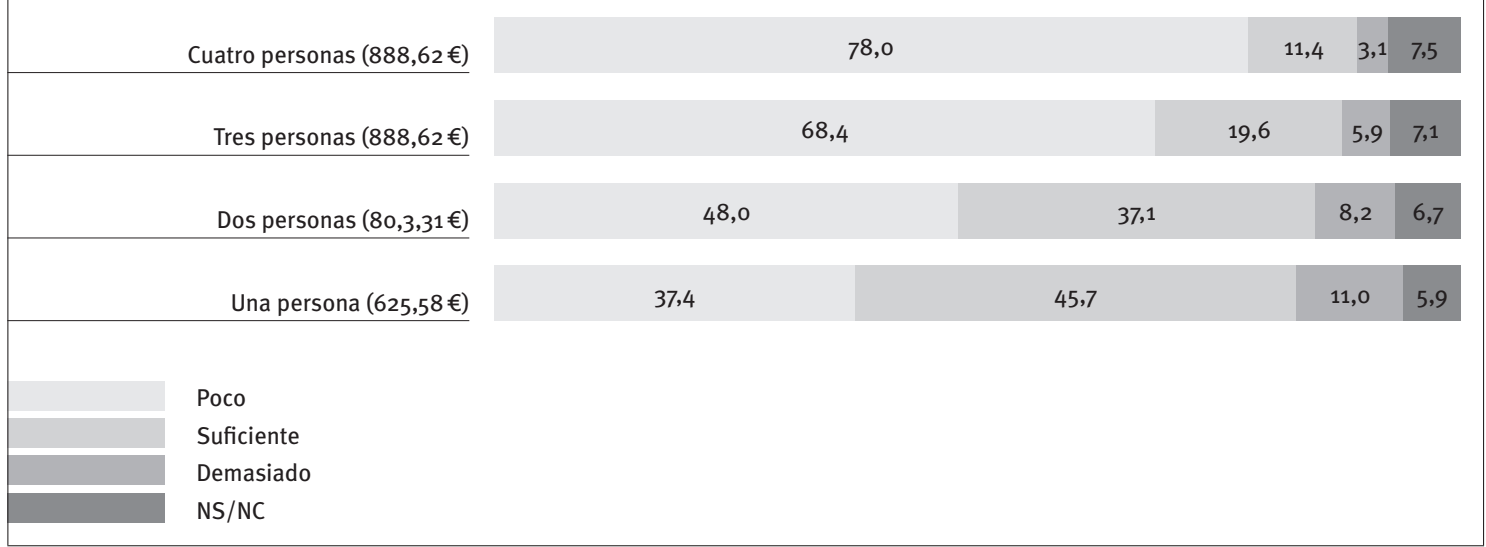

Fuente: Gizaker (2017).

también, y sobre todo, entre los analistas y decisores, incapaces de salir de este marco interpretativo reductor.

A pesar de este efecto neutralizador, una ligera mayoría de la sociedad vasca $(51,1 \%)$ está en desacuerdo con la idea de que el Gobierno Vasco no puede afrontar el coste de la RGI, frente al 19,9\% que estaría de acuerdo. Tres de cada diez no se decantan ni por el acuerdo ni por el desacuerdo. Es significativamente mayor el acuerdo entre quienes profesan ideología de derecha $(28,7 \%)$, y el desacuerdo entre los de izquierda $(62,1 \%)$ y estudiantes $(69,1 \%)$.

En un breve resumen de lo descrito, puede afirmarse que la sociedad vasca ha naturalizado y hecho propia la existencia de la RGI, la acepta y se enorgullece de ella, a pesar de que tal posición la mantenga en un entorno de discursos laboralizados, con omnipresencia de concepciones basadas en la preferencia de los nacionales. Por otro lado, nada extraño ni que no suceda en otros contextos geográficos. Pasarán décadas, siglos acaso, para que el cosmopolitismo metodológico suceda y sustituya al nacionalismo metodológico.

Las consecuencias de la aceptación del coste se constatan cuando un $82,8 \%$ piensa que es legítimo conceder la RGI a personas de salario bajo, o un $90,3 \%$, a quienes perciben una pensión baja, sin que haya diferencias significativas ni en uno ni en otro caso. Asimismo, es interesante profundizar en la opinión sobre las cuantías según número de personas por hogar (Gráfico 15). A medida que aumenta el número de miembros de la unidad de convivencia, mayor insuficiencia percibe la sociedad vasca en las cuantías. En cuanto a diferencias significativas, mientras que a los votantes de izquierda tiende a parecerles insuficiente la cuantía, a los derecha les parece suficiente o en demasía.

Como hemos adelantado, la visión de las políticas sociales como fuente de cohesión y la cohesión como base de la inversión social, no sólo pragmática y autocentrada en un funcionamiento menos conflictivo de la sociedad, tardará en abrirse camino y requiere de mucha pedagogía social y de cambio de mentalidades. Exige, en suma, un cambio cultural profundo. La protección social sigue envuelta de una leyenda negra, y muy probablemente nos encontramos con dos fenómenos superpuestos: 1) en principio, la ciudadanía no es capaz de identificar qué son las ayudas (o protecciones) sociales; y 2) en segundo, se identifican o con pérdida o con fraude. Esta opinión no es privativa de esta encuesta, sino que es recurrente en las realizadas por el Gabinete de Prospección Sociológica del Gobierno Vasco. Cuando se consulta a la ciudadanía vasca si está extendido o no el fraude en las prestaciones de las ayudas sociales, el 48,5\%, casi la mitad, piensa que está muy extendido; otro tercio (31,8\%) cree que opera un fraude similar al de otras prestaciones; y, finalmente, sólo un 6,4\% de 


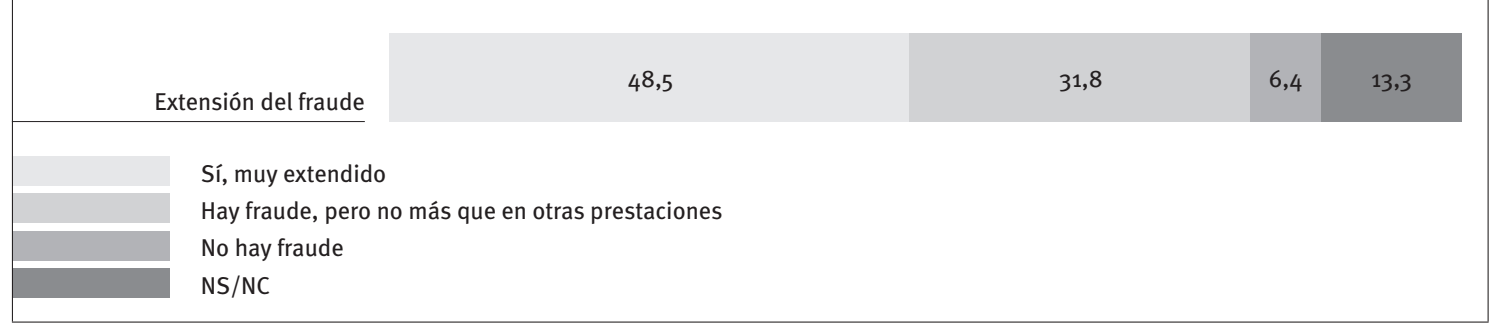

Fuente: Gizaker (2017).

la población estima que no hay fraude (Gráfico 16). No contesta o dice no saber el 13,3\%. Dicho de otra manera, el $80,3 \%$ de los vascos y vascas estima que el fraude está muy extendido, que prácticamente es universal. La única diferencia significativa deriva de la nacionalidad, su máxima extensión es intensificada por los de nacionalidad española y es aminorada por los de nacionalidad extranjera.

En consecuencia, el 93,1\% de las personas están de acuerdo en que Lanbide debe agilizar las tramitaciones y perseguir los incumplimientos y el fraude; el 90,5\% piensan que debe mejorar las tramitaciones en plazo corto; un 94,6\% están de acuerdo con que se debe perseguir el fraude, sea cual sea y proteger el sistema para quienes verdaderamente lo necesitan; $y$, en contraposición, el $88 \%$ declaran que debe exigirse la disponibilidad para el trabajo o la formación en el empleo a todos los perceptores de la RGI.

\subsection{Una foto de contexto}

La crisis económica suele usarse como causa para explicar el cambio de opiniones y percepciones. Pero parece más verosímil la idea de que la crisis, aprovechando la ocasión que faculta, se usa más profusamente como excusa para poner en marcha lecturas de la realidad preexistentes que sostienen que los servicios sociales, o la política social por extensión, son inviables económicamente y deben ser revisados - por supuesto, a la baja-. Determinados sectores sociales ya sostenían este punto de vista en tiempos de bonanza económica. Es, por tanto, más una elección ideológica que una fatalidad de las coyunturas.

En los datos anteriores, hemos recurrido a la encuesta realizada por Gizaker. Ahora deseamos valernos de algunas cuestiones, que, desperdigadas, se han preguntado demoscópicamente en los últimos años sobre esta materia y aledañas, para un análisis de contexto, para intentar describir cuál es el espíritu de la época y para poder entender mejor los datos.

No sería descabellado afirmar que, desde hace años, se ha ido instalando en la mentalidad de nuestras sociedades la idea de que somos personas hechas a nosotras mismas, sin mediación social y en un marco sin regulación institucional. Luego en consecuencia, a nadie debemos nada, porque de nadie hemos recibido nada. Todo esto se aviene perfectamente con la práctica culpabilizadora de la persona: 'posee lo que se merece' (véase nota 11).

De nuestro imaginario, se ha ido adueñando un pensamiento que legitima la secesión de los triunfadores, que habiendo atravesado el puente, deciden volarlo para que únicamente unas pocas personas elegidas puedan cruzarlo. Se sustituye una realidad meritocrática, que ha funcionado en las últimas décadas por otra aristocratizante $y$, aunque muy lentamente, emergen las primeras señales de lo que Luis Moreno (2012) ha descrito como ascenso del 'individualismo posesivo', o de lo que de otra manera María Silvestre (2014) ha denominado 'individualismo des-protegido'13. Esta actitud recela de la transferencia de solidaridad intrasocial y, en todo caso, está dispuesta a aportar, pero a condición de recibir en la misma medida o cantidad equivalente.

En el DeustoBarómetro Social ${ }^{14}$ de verano de 2014 se preguntaba en este sentido, y de las respuestas emerge la imagen de una sociedad descontenta, que se autopercibe como ‘contribuyente neta’ (Gráfico 17). No llega a un $20 \%$ el porcentaje de quienes consideran que reciben más de lo que pagan o tanto como pagan (un 3,8\% dice que recibe más de lo que paga y un $15,6 \%$ afirma que igual), pero dos tercios de las personas vascas $(66,4 \%)$ declaran recibir menos de lo que pagan. Un $14 \%$ dice no tener opinión sobre al respecto.

${ }^{13}$ A esta actitud intrasocial, le corresponde la que a escala europea se da entre Estados, que, por un lado se están recentrando en sí mismos en perjuicio de la unión europea, y por otro muestran, según algunos autores, una 'fatiga de solidaridad', de forma que cada vez son menos partidarios de contribuir para la mejora de terceros países. Como dice Ignacio Sánchez Cuenca (2014: 165):

Con el 'no' a la Constitución Europea en Francia y Países Bajos en abril-mayo de 2005 y la proliferación de la llamada 'fatiga de solidaridad' en Alemania a costa de la unificación y lo que allí se consideró que eran unas excesivas contribuciones al presupuesto europeo ('Europa', se decía, 'es cuando los Gobiernos acuerdan algo y Alemania paga'), estos países se sumaron a los ya que venían mostrando un euroescepticismo más consolidado (Dinamarca, Suecia o el Reino Unido). Mientras, en el sur de Europa crecía el europeísmo al hilo de una convergencia económica sin precedentes. Silvestre. 


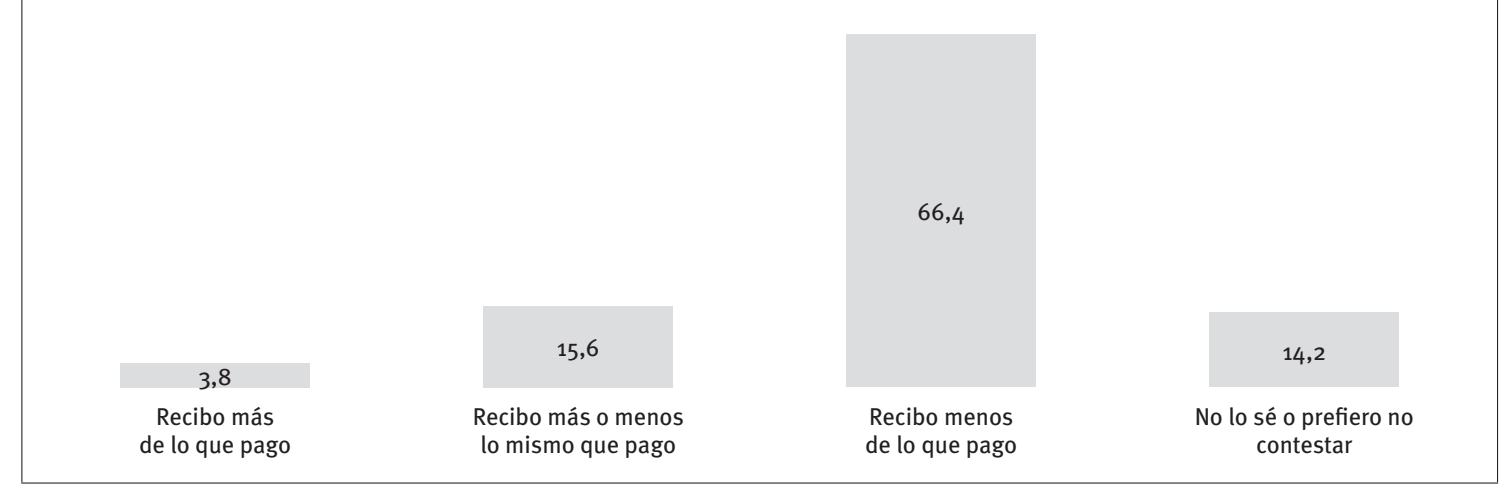

Fuente: Universidad de Deusto (2014).

Gráfico 18. Existencia del fraude según la ciudadanía vasca. Euskadi, 2011 (\%)

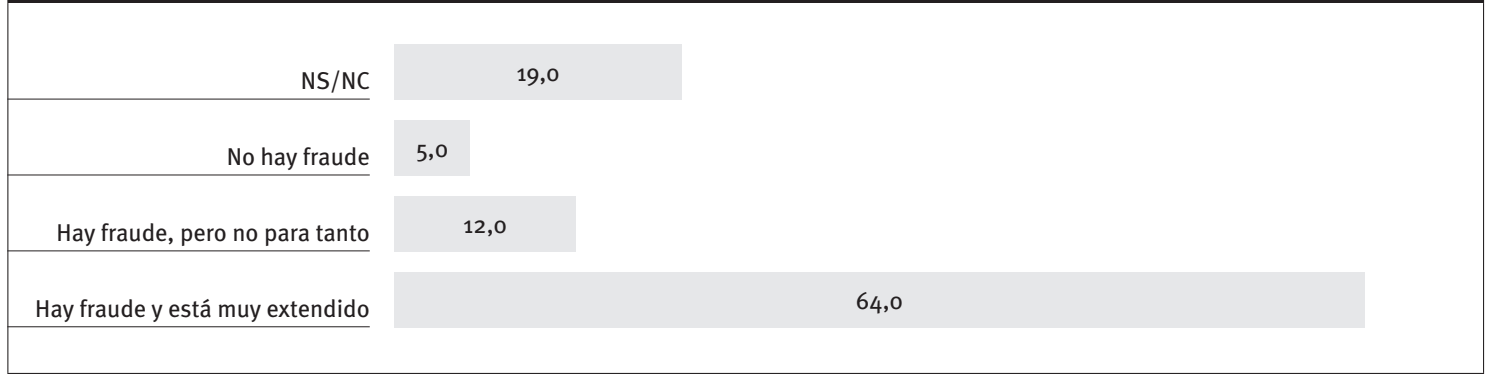

Fuente: Gabinete de Prospección Sociológica (2011).

A partir de estos datos, no puede decirse que comencemos nuestra travesía de contexto desde un buen punto de partida, porque nos indican desde dónde se ve hoy la vinculación social que debe nutrir la textura moral imprescindible para la cohesión social. La aportación neta que cada uno cree realizar y de la que el resto de la sociedad se aprovecharía menoscaba la transferencia de solidaridad incondicionada, dando lugar a varios círculos (los de la desconfianza y resentimiento, sobre todo) de los que habla el grupo redactor del capítulo 6 del último Informe Foessa (Zubero et al., 2014) $)^{15}$.

${ }^{15}$ En este texto (“¿Qué sociedad saldrá de la actual crisis? ¿Qué salida de la crisis impulsará esta sociedad?") coordinado por Imanol Zubero, el 'círculo de la desconfianza' aparece cuando la "corrupción, real o percibida (consecuencia en ocasiones de la propia lucha contra la corrupción y las noticias que genera), refuerza la desafección institucional, el desapego político y el relativismo ético, lo que favorece el desarrollo de la corrupción. La consecuencia es el debilitamiento de la cultura cívica y su sustitución por una cultura cínica” (ibídem: 241). El 'círculo del resentimiento' se da cuando el "asalariado medio, el que tiene nómina, siente que está perfectamente controlado por Hacienda; sin embargo, considera que otras personas, menos controladas que él (profesionales liberales, autónomos, rentas más altas), defraudan, lo que le provoca un profundo malestar, que le lleva a relacionarse con los impuestos en términos exclusivamente de coerción, por lo que exigirá permanentemente recibir servicios que supongan un 'retorno' equivalente a los impuestos que paga. El resultado es la conversión del ciudadano en cliente, lo que dificulta la fundamentación normativa de la fiscalidad, su consideración como deber de solidaridad, para quedar reducida a mera exacción o, en el mejor de los casos, a inversión privada a la espera de contraprestación en forma de servicios provistos públicamente pero consumidos individualmente" (ibídem).
Este dato se retroalimenta con otro sobre la presencia del fraude. El Gabinete de Prospección Sociológica realizó en 2011 un estudio en el que se afirmaba que el Gobierno Vasco estaba realizando un mayor control y seguimiento ante las prestaciones de las ayudas sociales (RGI) y se consultaba a la sociedad vasca si estaba o no de acuerdo con esta iniciativa: el $75 \%$ se mostraba de acuerdo con que se intensificase el control, un $4 \%$ no se decantaba y tan sólo un $8 \%$ estaba en desacuerdo. El $13 \%$ no contestaba.

Este posicionamiento se sustentaba en una opinión igualmente sólida que afirmaba la omnipresencia del fraude, por lo que el control era inevitable: el $64 \%$ de la población vasca afirma que hay un fraude muy extendido; un $12 \%$, que sí existe, pero no tan extendido; y se reduce a un $5 \%$ el porcentaje de los que niegan la existencia del fraude; mientras que una de cada cinco personas encuestadas (19\%) no responde (Gráfico 18).

Esta visión se refuerza cuando se consulta por el grado de protección a diferentes colectivos sociales desfavorecidos. Estos datos son realmente preocupantes, y aunque somos conscientes de que estas visiones son injustas con gran parte de la realidad, estamos en el ámbito subjetivo de la visión o percepción de la sociedad. Esto es lo que se ve, no necesariamente lo que hay. 
Pero en lo que se ve, prolifera el principio de la prioridad nacional inversa y el único colectivo que se percibe como protegido por parte de los vascos es el de las personas inmigrantes ${ }^{16}$ (Gráfico 19). Ningún otro colectivo tendría mucha o bastante protección. Según estos datos, las personas inmigrantes estarían 'sobreprotegidísimas' para el $63 \%$ de la sociedad vasca, siendo además ésta una de las respuestas más rotundas, porque sólo el $8 \%$ dice no saber o no contesta, luego esta visión es compartida y nítida para los opinantes: se opina sin duda y con rotundidad sobre la sobreprotección que reciben los inmigrantes. Además, esta opinión es sostenida en el tiempo, porque porcentajes similares se daban en $2010(64 \%)$ y 2011 (62\%).

Estos datos casan de lleno con los que ofrece Ikuspegi-Observatorio Vasco de Inmigración a través de su Barómetro sobre actitudes hacia la inmigración de la sociedad vasca, que realiza anualmente desde 2007 y que incluye varios ítems relacionados con el uso de la RGI por parte del colectivo inmigrante. Al respecto, y frente a otros estereotipos asociados a la inmigración que muestran una menor presencia en nuestra sociedad, los vinculados a un mal uso de la RGI por parte de este colectivo - desincentivación de la búsqueda de empleo o acaparamiento de la ayuda- aparecen con fuerza y de manera recurrente, aun cuando en los últimos años han perdido algo de fuerza (Ikuspegi, 2016; 2017).

Tras la población inmigrante, ningún otro colectivo sobrepasaría el $22 \%$ de suficiente protección, cifra a la que llegan las personas pensionistas (22\%) o discapacitadas (20\%). Según la opinión de la sociedad vasca, tendríamos una estructura de protección que estaría penalizando el mero hecho de ser autóctono. Por eso hablamos del principio de prioridad nacional inversamente entendido y percibido, porque originalmente tal principio indica que, en todo caso y lugar, 'primero, para los de casa'. Lo contrario piensa la sociedad vasca: 'primero, para los foráneos'. Así, una gran mayoría piensa que -en este orden- la juventud, los desempleados, las mujeres trabajadoras, las familias con menores a su cargo, o las y los pensionistas se ven franca y absolutamente desprotegidos.

En esta misma encuesta, cuando se pregunta sobre la evolución que tendrá el Estado del bienestar, se piensa que los servicios públicos y las políticas de bienestar tenderán a empeorar en todos los contextos sociopolíticos, pero lo harán más intensamente en España, en cifra muy superior a Euskadi o Europa, que tendrán evoluciones similares (Tabla 1).

Gráfico 19. Distribución de las respuestas a la pregunta "¿podría decirme si cree que en la actualidad los grupos que le voy a mencionar reciben mucha/bastante o poca/ninguna protección por parte de las administraciones públicas?". Euskadi, $2012(\%)$

\begin{tabular}{|c|c|c|c|}
\hline Las y los jóvenes & 11,0 & \multicolumn{2}{|l|}{83,0} \\
\hline Las mujeres trabajadoras & 13,0 & \multicolumn{2}{|l|}{76,0} \\
\hline Familias con menores a su cargo & 14,0 & \multicolumn{2}{|l|}{72,0} \\
\hline Las y los parados & 16,0 & \multicolumn{2}{|l|}{78,0} \\
\hline Familias con discapacitados a su cargo & 18,0 & \multicolumn{2}{|l|}{61,0} \\
\hline Personas con mayores a su cargo & 19,0 & \multicolumn{2}{|l|}{65,0} \\
\hline Personas que viven solas & 19,0 & \multicolumn{2}{|l|}{68,0} \\
\hline Personas discapacitadas & 20,0 & \multicolumn{2}{|l|}{57,0} \\
\hline Las y los pensionistas & 22,0 & \multicolumn{2}{|l|}{69,0} \\
\hline Las y los inmigrantes & \multicolumn{2}{|r|}{63,0} & 29,0 \\
\hline Mucha o bastante & & & \\
\hline Poca o ninguna & & & \\
\hline
\end{tabular}

Fuente: Gabinete de Prospección Sociológica (2012).

${ }^{16}$ El filósofo Peter Singer (2003: 165) nos proporciona un ejemplo interesante de la forma normal de entender la prioridad de los nacionales:

En el año 2000, los norteamericanos dieron un total de 4 dólares por persona necesitada, o aproximadamente 20 dólares por familia, en donativos privados para ayuda externa. Los neoyorkinos, ricos o no, que vivían en el Sur de Manhattan el 11 de septiembre de 2001, recibieron una media de 5.300 dólares. Las diferencias entre estas cantidades simbolizan la forma en la cual, para mucha gente, el ámbito de la preocupación por otros se detiene en las fronteras de su propio país, si es que se extiende tan lejos. 'La caridad bien entendida empieza por uno mismo', dice la gente, y, de forma más explícita, 'debemos ocuparnos de la pobreza en nuestro propio país antes de intentar arreglar la de fuera'. Dan por hecho que las fronteras nacionales tienen valor moral y que es peor dejar necesitado a uno de nuestros conciudadanos que dejar en tal estado a un habitante de otro país. 
Tabla 1. Distribución de las respuestas a la pregunta "en el futuro, ¿cree que cada uno de los siguientes aspectos de la protección social mejorará, seguirá igual o empeorará?”. Euskadi, 2012 (\%)

\begin{tabular}{|l|c|c|c|c|c|}
\cline { 2 - 6 } \multicolumn{1}{c|}{} & Mejorarán & $\begin{array}{c}\text { Seguirán } \\
\text { igual }\end{array}$ & Empeorarán & NS/NC & Total \\
\hline Europa & 17 & 34 & 36 & 13 & 100 \\
\hline España & 9 & 23 & 64 & 4 & 100 \\
\hline Euskadi & 14 & 38 & 44 & 4 & 100 \\
\hline La atención sanitaria & 15 & 40 & 43 & 3 & 100 \\
\hline Los servicios y ayudas sociales & 11 & 36 & 49 & 4 & 100 \\
\hline El sistema público de pensiones & 8 & 40 & 48 & 5 & 100 \\
\hline La conciliación laboral/familiar & 11 & 38 & 45 & 7 & 100 \\
\hline La protección del desempleo & 10 & 31 & 55 & 4 & 100 \\
\hline El acceso a la primera vivienda & 10 & 30 & 56 & 4 & 100 \\
\hline El sistema educativo público & 12 & 40 & 44 & 4 & 100 \\
\hline
\end{tabular}

Fuente: Gabinete de Prospección Sociológica (2012).

Situados en Euskadi, se piensa que la protección social empeorará en atención sanitaria, en servicios y ayudas, en pensiones, en la conciliación, en educación y, sobre todo, en la protección del desempleo y en el acceso a la primera vivienda. Dentro de lo que cabe, en este escenario de empeoramiento general, los valores de quienes piensan que las cosas seguirán igual corresponden a sanidad, pensiones o educación. Un $40 \%$ sostiene que no habrá empeoramiento ni mejora en estos campos.

Cuando se pregunta sobre el Estado del bienestar, la respuesta es ambivalente y se mezclan, por un lado, las tareas que debe atender y, por otro, dudas sobre su viabilidad. La Tabla 2 recoge las opiniones de la sociedad vasca sobre cuatro dimensiones del Estado del bienestar.

Tabla 2. Distribución de las respuestas a la pregunta “¿cuál es su grado de acuerdo con las siguientes frases?". Euskadi, 2012 (\%)

\begin{tabular}{|l|c|c|c|c|}
\cline { 2 - 5 } \multicolumn{1}{l|}{} & $\begin{array}{c}\text { Más bien de } \\
\text { acuerdo }\end{array}$ & $\begin{array}{c}\text { Más bien en } \\
\text { desacuerdo }\end{array}$ & NS/NC & Total \\
\hline $\begin{array}{l}\text { El principal } \\
\text { problema es } \\
\text { la falta de un } \\
\text { control del } \\
\text { dinero que } \\
\text { se emplea en } \\
\text { políticas públicas }\end{array}$ & 84 & 7 & 8 & 100 \\
\hline $\begin{array}{l}\text { Defender el } \\
\text { Estado del } \\
\text { bienestar es } \\
\text { prioritario } \\
\text { para cualquier } \\
\text { sociedad } \\
\text { solidaria }\end{array}$ & 81 & 10 & 9 & 100 \\
\hline $\begin{array}{l}\text { Los recortes } \\
\text { en políticas de } \\
\text { bienestar no } \\
\text { servirán para } \\
\text { salir de la crisis }\end{array}$ & 68 & 22 & 10 & 100 \\
\hline $\begin{array}{l}\text { El Estado del } \\
\text { bienestar } \\
\text { ha crecido } \\
\text { demasiado y } \\
\text { se ha hecho } \\
\text { insostenible }\end{array}$ & 59 & 32 & 9 & 100 \\
\hline
\end{tabular}

Fuente: Gabinete de Prospección Sociológica (2012).
Como podemos observar, por un lado, ocho de cada diez vascos piensan que el Estado del bienestar es prioritario para la solidaridad social, pero igual porcentaje declara que existe falta de control del uso del dinero público. Por otra parte, se piensa que el Estado del bienestar es económicamente inviable, a la vez que se sostiene que los recortes no solventarán los efectos de la crisis. Podemos concluir diciendo que en esta amalgama de posiciones late la voluntad de hacer cuadrar todos los aspectos positivos del Estado del bienestar, eludiendo sus dilemas. De un lado, la población aparece como ferviente partidaria del Estado del bienestar, pero de otro, estima que se ha convertido en una maquinaria gigante e inmanejable. En el fondo, estamos ante un conjunto de verdades sociales que, por repetidas, son aceptadas sin ninguna conciencia de su contradicción intrínseca.

Como corolario de todas las anteriores opiniones, se piensa que la prioridad del Estado del bienestar consiste en: ofrecer servicios universales básicos (como la sanidad, la educación y las pensiones) para todas las personas ( $52 \%$ ), asegurar la igualdad de oportunidades de todas las personas y un mínimo de protección cuando sea necesaria (35\%), y ayudar sólo a las personas más desfavorecidas de la sociedad (11\%).

Finalmente, cuando a las mismas personas se les consulta sobre cuáles deberían ser las áreas a preservar y en las que no debería llevarse a cabo ningún recorte, el $75 \%$ de la población vasca señala que en atención sanitaria, el $38 \%$ en educación, el $31 \%$ en pensiones, el $23 \%$ en prestaciones de desempleo y el $11 \%$ en servicios sociales. Con porcentajes menores, aparecen la investigación (6\%), el acceso a la vivienda de protección oficial (6\%) y el impulso del euskara (2\%). Sólo un $2 \%$ declara que no deberían practicarse recortes en ningún ámbito.

\section{Conclusiones}

Las opiniones y actitudes de la sociedad vasca en torno a la RGI nos confirman que la realidad percibida 
y la realidad social no siempre van de la mano, y que estas percepciones condicionan claramente el análisis y la propia percepción de esa realidad social.

Partiendo de esta premisa, una primera idea que cabe destacar es que el conocimiento en torno a la RGI es escaso, difuso y disperso; de esta forma, 'se conoce de oídas, pero no de sabidas'. Del mismo modo, aparecen recurrentemente ideas y afirmaciones que se sitúan en cierta ambivalencia con respecto a la valoración de la RGI. Si bien se cree que sirve para hacer frente a la pobreza y para cohesionar a la sociedad, no es menos cierto que algunas ideas contrarias, generalmente no sustentadas en datos y hechos reales, tienen un gran calado dentro de la sociedad vasca.

Entre éstas, pueden señalarse la idea de la existencia de un fraude considerable dentro de la RGI; la desincentivación que produce en la búsqueda de empleo; o el alto grado de protección que se ofrece al colectivo inmigrante, en detrimento del autóctono. Estas percepciones campan en un escenario en el que prevalecen visiones muy asociadas a la centralidad del empleo, a la responsabilidad individual de la situación o a una perspectiva en la que la preferencia nacional sigue manteniendo la hegemonía dentro del imaginario social.

Ampliando este planteamiento al Estado del bienestar en su conjunto y a los servicios sociales, es interesante subrayar también cómo algunos mantras neoliberales que han tomado fuerza en el periodo de recesión, pero que ya existían previamente, han calado en la sociedad vasca y se repiten recurrentemente, por ejemplo, el referido a la insostenibilidad del sistema o la inviabilidad económica de los servicios sociales. Sin embargo, la ambivalencia anteriormente ya citada para la RGI se da de nuevo en este caso, en el que junto con estas ideas aparecen otras, como la necesidad del Estado del bienestar o su papel positivo.

El lugar que la sociedad vasca adjudica a los servicios sociales nos lleva a pensar que son relativamente invisibles y desconocidos, y que, en todo caso, se perciben como un ámbito en el que no termina de haber un control exhaustivo y, por tanto, en donde prolifera un fraude in- y des-controlado. Además, mucho nos tememos que el conocimiento de qué puedan ser los servicios sociales no es tan nítido y está menos extendido de lo que pudiera parecer, porque mientras que la sanidad, la educación y las pensiones tienen una mayor materialidad en el imaginario de la sociedad vasca, los servicios sociales son una realidad más gaseosa y con una ligera connotación negativa, identificada con algo etéreo llamado ayudas sociales, como si por ella y a través de ella se aprovechasen y se colasen personas sospechosas de percibir protecciones que o no se merecen -las personas extranjeras-o que no las necesitan. Sólo desde ahí se entiende que se diga que la función del Estado del bienestar es suministrar un mínimo de protección cuando sea necesario o que la ayuda debe beneficiar sólo a las personas más desfavorecidas de la sociedad.

En consecuencia, estas opiniones nos indican que los servicios sociales, a pesar de estar muy presentes en las prácticas y necesidades cotidianas de muchas personas, padecen de desconocimiento y adolecen de reconocimiento, porque la sola referencia al término social levanta suspicacias como ámbito sospechoso, y también muy probablemente por efecto directo o indirecto de la sobrevaloración de la inclusión laboral como garantía de la integración social, incluso en un mundo poslaboral como el actual.

Corresponde a instituciones, entidades y compañeros de viaje trabajar en esta labor de visualización de los servicios sociales, proceder a su legitimación, no vaya a ser que terminemos cayendo, por diversas y muy incomprensibles razones, en el 'círculo del sentimiento de desamparo’, cuando si, por un lado, son:

Las clases bajas y la clase profesional de cualificación media las que más están perdiendo con la crisis, [por otro] la recomposición del discurso ciudadano sobre el Estado del bienestar (valoración de los servicios sociales, cultura fiscal) en España parece estar siendo impulsada por unas clases medias que se sienten maltratadas por el poder político y agraviadas frente a otros colectivos sociales que, en su opinión, reciben mucha más ayuda y protección del Estado. El resultado es la ruptura de la universalidad y la conversión del espacio de las políticas sociales en un campo de lucha entre grupos de interés (Zubero et al., 2014: 422).

Para acabar, el Informe Foessa sostenía que es preciso:
Remoralizar nuestras preferencias como ciudadanas y ciudadanos, depurando normativamente nuestros intereses particulares con el fin de incorporar a nuestras reivindicaciones la perspectiva y las necesidades de los individuos y los grupos excluidos, para reforzar la capacidad regulativa del Estado a la hora de impulsar una fiscalidad progresiva que permita sostener un sistema universalista de bienestar (Zubero et al., 2014: 428).

Remoralizar la sociedad y recuperar el sentido (moral) de la economía son indispensables para reducir los sentimientos de agravio tan extendidos a día de hoy, y para así re-poner la solidaridad cuestionada. Que la crisis no sea la excusa, porque no es la causa. 


\section{Bibliografía referenciada}

ALONSO, L. E. (2007): La crisis de la ciudadanía laboral, Barcelona, Anthropos.

- (2001): Trabajo y posmodernidad: el empleo débil, Madrid, Fundamentos.

ANDERSEN, T.; y SVARER, M. (2014): “The role of workfare in striking a balance between incentives and insurance in the labour market", Economica. vol. 81, n- 321, págs. 86-116.

ATTAC MADRID (2013): "Renta básica, capacidades y necesidades. Philippe Van Parijs” («http:// ilprentabasica.org/renta-basica-capacidadesy-necesidades-philippe-van-parijs/>) [síntesis de MYLONDO, B.; y COTTIN-MARX (2013): “De chacun (volontairement) selon ses capacités à chacun (inconditionnellement) selon ses besoins. Entretien avec Philippe Van Parijs", Mouvements, $\mathrm{n}-73$ ].

AYALA, L. (2000): Las rentas mínimas en la reestructuración de los Estados de Bienestar, Madrid, Consejo Económico y Social.

BECK, U. (2002): Libertad o socialismo, Barcelona, Paidós.

- (2000): Un mundo feliz. La precarización del trabajo en la era de la globalización, Barcelona, Paidós.

BRODKIN, E.; y MARSTON, G. (eds.) (2013): Work and Welfare State. Street Level Organizations and Workfare Politics, Washington, Georgetown University Press.

CABALLERO, A.; y VILASECA, S. (2003): "Ya no hay lugares vacíos donde arrojar los desperdicios humanos. Entrevista con Zygmunt Bauman", El Viejo Topo, ํㅜ 183, págs 10-17.

CASTEL, R. (1997): Las metamorfosis de la cuestión social. Una crónica del salariado, Buenos Aires, Paidós.
GABINETE DE PROSPECCIÓN SOCIOLÓGICA (2012): El Estado de Bienestar, Vitoria-Gasteiz, Gobierno Vasco.

- (2011): Percepción sobre el control de ayudas sociales, políticas activas de empleo y vacaciones, Vitoria-Gasteiz, Gobierno Vasco.

GARCÍA ROMERO, M. B. (1999): Rentas mínimas garantizadas en la Unión Europea, Madrid, Consejo Económico y Social.

GIZAKER (2017): "Estudio sobre renta de garantía de ingresos (RGI). CAV. C.889. Informe gráfico de resultados", en GOBIERNO VASCO, Documento de bases para la mejora de la renta de garantía de ingresos, Vitoria-Gasteiz, Gobierno Vasco.

IKUSPEGI-OBSERVATORIO VASCO DE INMIGRACIÓN (2017): Barómetro 2017. Presentación, Bilbao, Universidad del País Vasco.

- (2016): Barómetro 2015. Percepciones y actitudes hacia la población de origen extranjero, Bilbao, Universidad del País Vasco.

JUDT, T.; y SNYDER, T. (2012): Pensar el siglo XX, Madrid, Taurus.

LAPARRA, M. (2004): "La travesía del desierto de las rentas

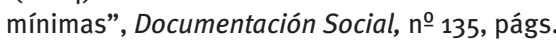
57-76.

MACLEAVY, J. (2015): "Workfare and resistance in the US: The quietude and ineffectiveness of progressive welfare politics post 1996", The Geographical Journal, vol. 181, nํㅜ 3, págs. 259-267.

MONDE DIPLOMATIQUE, LE (2017): "Bienaventurados los pobres", Le Monde Diplomatique, $\mathrm{n} \div 263$, pág. 7 .

MORENO, G.; y FULLAONDO, A. (2013): “La evolución del proceso de integración del colectivo inmigrante en la Comunidad Autónoma del País Vasco", 
en BLANCO, C.; MORENO, G.; y COLLADO, A. (coords.), VII Congreso Migraciones internacionales en España, Bilbao, Universidad del País Vasco.

MORENO, G; FOUASSIER, M.; y MARTÍN, M. J. (2015): "Política de garantía de ingresos y población de origen extranjero en el País Vasco. Evidencias empíricas y deslegitimación discursiva", Zerbitzuan, no -58 , págs. 51-6o [khttps://doi. org/10.5569/1134-7147.58.05'].

MORENO, L. (2012): La Europa asocial. ¿Caminamos hacia un individualismo posesivo?, Barcelona, Península.

SÁNCHEZ CUENCA, I. (2014): La impotencia democrática. Sobre la crisis política de España, Madrid, Libros de la Catarata.

SCHUTZ, A. (1974): Estudio de teoría social, Buenos Aires, Amorrortu.

SHAVER, S. (2002): "Australian welfare reform: From citizenship to supervisión", Social Citizenship \& Administration, vol. 36, nำ 4, págs. 331-345.

SHORT (2015): The Supplemental Poverty Measure: 2014 , serie Current Population Reports, septiembre, United States Census Bureau [<https://www. census.gov/content/dam/Census/library/ publications/2015/demo/p6o-254.pdf)].

SIIS CENTRO DE DOCUMENTACIÓN Y ESTUDIOS (2017): Características de las prestaciones de garantía de ingresos en las comunidades autónomas,
Donostia-San Sebastián, SIIS Centro de Documentación y Estudios [<http://www.siis. net/es/investigacion/ver-estudio/521/>].

SILVESTRE, M. (2014): De un individualismo placentero y protegido a un individualismo no placentero $y$ desprotegido, serie Documentos de Trabajo del VII Informe sobre Exclusión y Desarrollo Social en España, no 6.3, Madrid, Fundación Foessa [<http://www.foessa2014. es/informe/uploaded/documentos trabajo/23102014160137_5634.pdfı].

SINGER, P. (2003): Un solo mundo. La ética de la globalización, Barcelona, Paidós.

SOWELL, T. (1990): Conflicto de visiones, Buenos Aires, Gedisa.

UNIVERSIDAD DE DEUSTO (2014): DeustoBarómetro Social II. Informe de resultados, Universidad de Deusto [〈http://barometrosocial.deusto.es〉].

WADDAN, A. (2003): "Redesigning the welfare contract in theory and practice: Just what is going in the USA?", Journal of Social Policy, vol. 32, $\mathrm{n}-1$, págs. 9-35.

ZUBERO, I. et al. (2014): “¿Qué sociedad saldrá de la actual crisis? ¿Qué salida de la crisis impulsará esta sociedad?", VII. Informe sobre exclusión y desarrollo social en España. 2014, Madrid, Fundación Foessa [<http://www.foessa2014. es/informe/uploaded/capitulos/pdf/o6_ Capitulo_6.pdf>]. 